\title{
¿Soil Moisture Control of Precipitation Reevaporation over a Heterogeneous Land Surface
}

\author{
Yu Cheng, ${ }^{\text {a }}$ Pak Wah Chan, ${ }^{\text {a }}$ Xin Wei, ${ }^{\mathrm{a}}$ Zeyuan Hu, ${ }^{\mathrm{a}}$ Zhiming KuAng, ${ }^{\mathrm{a}, \mathrm{b}}$ And Kaighin A. McCOLl ${ }^{\mathrm{a}, \mathrm{b}}$ \\ ${ }^{\text {a }}$ Department of Earth and Planetary Sciences, Harvard University, Cambridge, Massachusetts \\ b School of Engineering and Applied Sciences, Harvard University, Cambridge, Massachusetts
}

(Manuscript received 2 March 2021, in final form 9 July 2021)

\begin{abstract}
Soil moisture heterogeneity can induce mesoscale circulations due to differential heating between dry and wet surfaces, which can, in turn, trigger precipitation. In this work, we conduct cloud-permitting simulations over a $100 \mathrm{~km} \times 25 \mathrm{~km}$ idealized land surface, with the domain split equally between a wet region and a dry region, each with homogeneous soil moisture. In contrast to previous studies that prescribed initial atmospheric profiles, each simulation is run with fixed soil moisture for 100 days to allow the atmosphere to equilibrate to the given land surface rather than prescribing the initial atmospheric profile. It is then run for one additional day, allowing the soil moisture to freely vary. Soil moisture controls the resulting precipitation over the dry region through three different mechanisms: as the dry domain gets drier, (i) the mesoscale circulation strengthens, increasing water vapor convergence over the dry domain, (ii) surface evaporation declines over the dry domain, decreasing water vapor convergence over the dry domain, and (iii) precipitation efficiency declines due to increased reevaporation, meaning proportionally less water vapor over the dry domain becomes surface precipitation. We find that the third mechanism dominates when soil moisture is small in the dry domain: drier soils ultimately lead to less precipitation in the dry domain due to its impact on precipitation efficiency. This work highlights an important new mechanism by which soil moisture controls precipitation, through its impact on precipitation reevaporation and efficiency.
\end{abstract}

KEYWORDS: Density currents; Precipitation; Cloud resolving models

\section{Introduction}

Soil moisture plays an important role in land-atmosphere interaction processes across spatial scales ranging from kilometers to thousands of kilometers and temporal scales ranging from days to years (Seneviratne et al. 2006; Fischer et al. 2007; McColl et al. 2017). In particular, soil moisture affects soil heat capacity (Entekhabi et al. 1996), the partition of net radiation into sensible and latent heat fluxes (Gu et al. 2006), surface albedo (Idso et al. 1975), available radiation (Eltahir 1998), and cloud formation (Ray et al. 2003). Consequently, the accuracy of numerical weather forecasts (Gallus and Segal 2000; Martin and Xue 2006; Van Weverberg et al. 2010) and climate models (Pielke et al. 1999; Dirmeyer 2000; Seneviratne et al. 2013; Moon et al. 2019) are often sensitive to soil moisture, which is regarded as one of the most important boundary conditions for improved climate predictability (Dirmeyer 1995). Causal impacts of soil moisture on subsequent precipitation are of particular interest and have been investigated with field observations (e.g., Betts and Ball 1998; Eltahir 1998; Taylor and Lebel 1998; Findell and Eltahir 2003; Alfieri et al. 2008; Taylor et al. 2012; Tuttle and

\footnotetext{
๑ Denotes content that is immediately available upon publication as open access.
}

Chan's current affiliation: College of Engineering, Mathematics and Physical Sciences, University of Exeter, Exeter, United Kingdom.

Corresponding author: Kaighin A. McColl, kmccoll@seas. harvard.edu
Salvucci 2016) and numerical simulations (e.g., Schär et al. 1999; Pal and Eltahir 2001; Cheng and Cotton 2004; Hohenegger et al. 2009; Van Weverberg et al. 2010).

One mechanism by which soil moisture can cause precipitation is analogous to a land-sea breeze circulation (Segal and Arritt 1992; Miller et al. 2003). Differential heating between a dry patch of soil (analogous to the "land") and a wet patch (analogous to the "sea") creates a mesoscale circulation. The circulation transports atmospheric water vapor from the wet patch to the dry patch, and the rising branch of the circulation over the dry patch promotes precipitation. Therefore, as soil moisture in the dry patch declines, precipitation over the dry patch becomes more likely, even as evaporation over the dry patch declines. Wet patches regularly occur in otherwise dry environments following rainfall, and mesoscale circulations associated with soil moisture heterogeneity have been observed to trigger convection in the Sahel (Taylor et al. 2010, 2011, 2012). As such, they have been the subject of many previous modeling studies (e.g., Anthes 1984; Ookouchi et al. 1984; Chen and Avissar 1994; Avissar and Liu 1996; Lynn et al. 1998; Cheng and Cotton 2004; Patton et al. 2005; Robinson et al. 2008; Cioni and Hohenegger 2018, hereafter CH18).

While these studies have provided valuable insight, they suffer from a common limitation: models are typically integrated over relatively short time periods (hours to days), meaning the results are quite sensitive to the choice of initial conditions, particularly the initial atmospheric sounding (e.g., $\mathrm{CH} 18)$. On the one hand, this is an understandable simplification, since wet patches of soil are transient, appearing after rainfall and disappearing due to evaporation on time scales of hours to days. On the other hand, such simulations 
fundamentally neglect coupling between the atmospheric profile and the land surface occurring on time scales longer than the model's short integration time. For example, one might reasonably expect that the atmosphere will be considerably warmer and drier over a drier land surface, all else being equal, particularly in regions where atmospheric convergence of moisture and heat are small. However, if this coupling occurs on time scales longer than the model's total simulation time, it will be neglected in the simulation.

As we will show, the neglected influence of the land surface on the prescribed initial atmospheric profile can be significant and has a profound effect on the soil moisture-precipitation relation. In this study, we run cloud-permitting simulations of a mesoscale circulation that forms over an idealized wet patch in an otherwise dry environment, similar to $\mathrm{CH} 18$. However, in contrast to previous studies, we first allow the atmosphere to equilibrate to the land surface state, before using the equilibrated atmospheric profile as an initial condition in the transient simulation of a wet patch. This approach preserves the coupling between the land surface and the atmospheric profile.

The main new impact of this coupling is on precipitation efficiency: drier soils cause drier atmospheres, which reevaporate more precipitation before it reaches the land surface. Previous studies (Schär et al. 1999; Cioni and Hohenegger 2017; CH18) have noted soil moisture impacts on large-scale precipitation efficiency (the ratio of surface precipitation to total moisture inflows), which is often well correlated (Sui et al. 2007) with the microphysical precipitation efficiency (the ratio of surface precipitation to the column-integrated condensation rate). Schär et al. (1999) proposed a mechanism in which drier soils (i) reduce moist entropy flux into the boundary layer, (ii) dilute boundary layer moist entropy by increasing the height of the boundary layer, and (iii) increase the level of free convection, which all act to decrease convective precipitation and the large-scale precipitation efficiency. Cioni and Hohenegger (2017) identified declines in conversion efficiency (the rate of conversion of cloud water to precipitation) with decreasing soil moisture in some cases. They attributed the decline of the conversion efficiency to attenuated peaks in cloud water over drier soils, which reduce the likelihood of exceeding cloud water conversion thresholds used in microphysics schemes. The mechanism we identify (drier soils cause more precipitation reevaporation) is distinct from both of these mechanisms. It will be shown that including the new mechanism reverses the sign of the soil moisture-precipitation relation typically identified in previous studies, from negative (drier soils in the dry patch cause more precipitation, as in, e.g., CH18) to positive (drier soils cause less precipitation).

This manuscript is organized as follows. In section 2, we describe the model setup and simulations conducted, in which soil moisture in the dry patch is systematically varied. In section 3, we describe the results of the simulations, and demonstrate the key role of precipitation reevaporation on precipitation efficiency, and on surface precipitation itself. In section 4 , we propose a conceptual model that summarizes the most important mechanisms in our simulations, relate our results to previous work on the topic, and discuss limitations of our simulations. Section 5 concludes the manuscript.

\section{Methods}

We use coupled simulations of the land surface model described by Lee and Khairoutdinov (2015) and the System for Atmospheric Modeling (SAM; version 6.11.1) originally introduced in Khairoutdinov and Randall (2003). The land surface model solves energy and moisture balance equations to determine atmospheric surface fluxes (Lee and Khairoutdinov 2015). The cloud-resolving model SAM solves the anelastic continuity, momentum, and scalar conservation equations, with prognostic thermodynamic variables being the liquid water/ice moist static energy, total nonprecipitating water, and total precipitating water (Khairoutdinov and Randall 2003). Following Smolarkiewicz and Grabowski (1990), the positive definite and monotonic scheme is used to advect all prognostic scalars. The longwave and shortwave radiation is computed following the National Center for Atmospheric Research (NCAR) Community Climate Model (CCM3) described in Kiehl et al. (1998). The subgrid-scale (SGS) model is the 1.5-order closure based on a prognostic SGS turbulent kinetic energy (Khairoutdinov and Randall 2003). Two different microphysics schemes are used: the single-moment scheme (SAM1MOM) introduced by Khairoutdinov and Randall (2003) and the double-moment scheme (M2005) introduced by Morrison et al. (2005). The single-moment scheme (SAM1MOM) predicts only the mixing ratios of hydrometeor species and parameterizes the number concentrations from an assumed size distribution and the predicted mixing ratio (Khairoutdinov and Randall 2003). The double-moment scheme (M2005) predicts both the mixing ratios and the number concentrations of hydrometeor species (Morrison et al. 2005), with the aim of improving parameterizations of the particle size distributions (Morrison et al. 2009). We use two different microphysics schemes to assess the sensitivity of our results to reasonable changes in microphysics.

The dimensions of the simulated domain (Fig. 1a) are approximately 100,25 , and $22 \mathrm{~km}$ in the $x, y$, and $z$ (vertical) directions, respectively, thus comparable to the heterogeneity length scale of 50-100 km (Chen and Avissar 1994; Lynn et al. 1998; Robinson et al. 2008) that maximizes moist convection over the dry patch. The domain size is smaller than that used in a similar previous study (CH18), and the equilibrium state is sensitive to domain size (not shown). However, the mesoscale circulations that form in our simulations are conceptually similar to those in $\mathrm{CH} 18$. We expect the mesoscale circulations formed in our simulations are robust to reasonable variations in domain size (see section 4a). The periodic horizontal domain has a spatial resolution of $250 \mathrm{~m}$, while the vertical domain has a finer resolution of $30 \mathrm{~m}$ near the surface and a coarser resolution of $200 \mathrm{~m}$ near the top. The domain is divided into two equal patches in the $x$ direction (Fig. 1a). No Coriolis force is applied. No mean wind is prescribed. While Froidevaux et al. (2014) showed that relaxing wind speeds back to prescribed, nonzero values can significantly alter the relation between local soil moisture and precipitation, this study focuses on the simpler case with no wind relaxation, consistent with previous studies (e.g., CH18). The center of the domain is at $8^{\circ} \mathrm{N}$ in the 
(a)

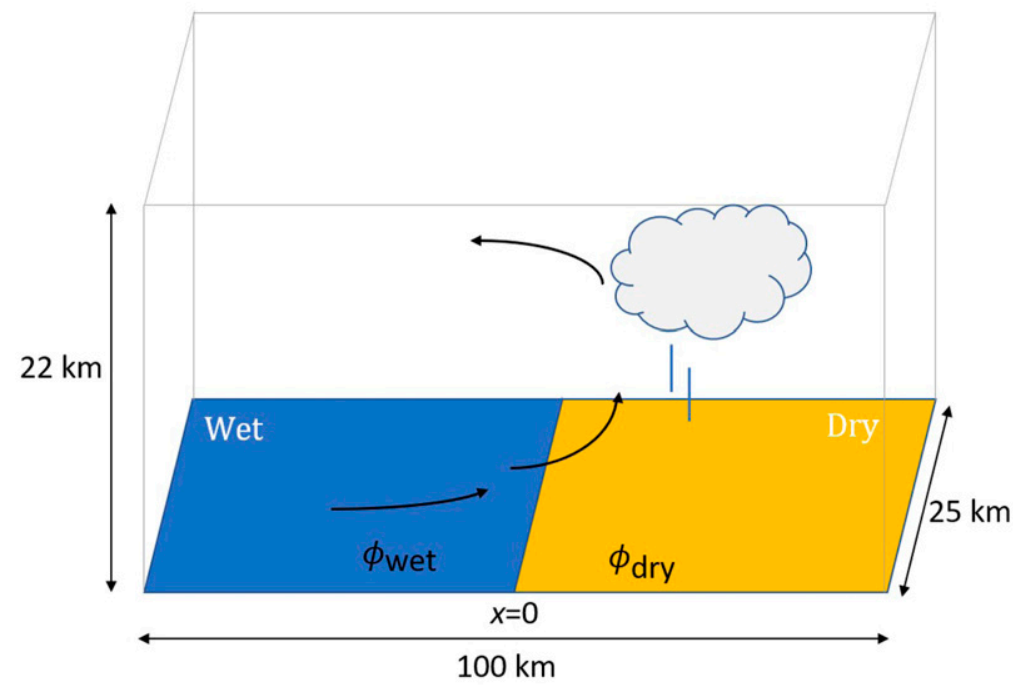

(b)

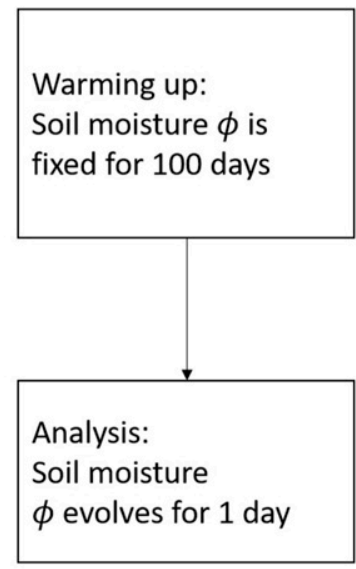

FIG. 1. Schematic of (a) soil moisture setup in the computational domain and (b) two steps of land-atmosphere simulations. In (a) $\phi_{\text {wet }}$ and $\phi_{\text {dry }}$ denote soil moisture of the wet patch and dry patch, respectively.

tropics to roughly mimic the Sahel region. The start date of the simulations is January 1, and there is no seasonal cycle; the diurnal cycle is retained. There are 9 layers of bare soil with the top layer being $1 \mathrm{~cm}$ and the bottom layer $15 \mathrm{~m}$ in depth. The initial temperature is around $27^{\circ} \mathrm{C}$ for the top soil and $25^{\circ} \mathrm{C}$ for the bottom soil. The initial wetness of soil is prescribed uniformly as shown in Table 1 . The soil type is silt loam with sand concentration being $17 \%$ and clay concentration $13 \%$ as described in Lee and Khairoutdinov (2015). We do not set a permanent wilting point or field capacity since bare soil is simulated without vegetation.

Soil moisture patches are fundamentally transient phenomena: they appear quasi randomly in the landscape following precipitation and then disappear on time scales of hours to days due to evaporation and runoff. Therefore, our analysis focuses on short time scales [ $O(1)$ day] relevant to weather forecasting, similar to previous work (e.g., Gallus and Segal 2000; Van Weverberg et al. 2010; Barthlott and Kalthoff 2011; CH18).

TABLE 1. List of experiments run in this study. There are 41 numerical experiments in total.

\begin{tabular}{lccc}
\hline \hline Numerical experiments & Initial soil moisture $\phi_{\text {dry }}(\%)\left(\mathrm{m}^{3} \mathrm{~m}^{-3}\right)$ & Initial soil moisture $\phi_{\text {wet }}(\%)$ & Microphysical scheme \\
\hline wet_01_100 & $1(0.0047)$ & 100 & SAM1MOM \\
wet_03_100 & $3(0.0140)$ & 100 & SAM1MOM \\
wet_05_100 & $5(0.0234)$ & 100 & SAM1MOM \\
wet_07_100 & $7(0.0327)$ & 100 & SAM1MOM \\
wet_10_100 & $10(0.0468)$ & 100 & SAM1MOM \\
wet_12_100 & $12(0.0561)$ & 100 & SAM1MOM \\
wet_15_100 & $15(0.0701)$ & 100 & SAM1MOM \\
wet_20_100 & $20(0.0935)$ & 100 & SAM1MOM \\
.. & $\ldots$ & $\ldots$ & $\ldots$ \\
wet_85_100 & $85(0.3974)$ & 100 & SAM1MOM \\
wet_01_99 & $1(0.0047)$ & 99 & SAM1MOM \\
wet_03_97 & $3(0.0140)$ & 97 & SAM1MOM \\
wet_05_95 & $5(0.0234)$ & 95 & SAM1MOM \\
wet_07_93 & $7(0.0327)$ & 93 & SAM1MOM \\
wet_10_90 & $10(0.0468)$ & 90 & SAM1MOM \\
wet_20_80 & $20(0.0935)$ & 80 & SAM1MOM \\
wet_30_70 & $30(0.1403)$ & 100 & SAM1MOM \\
M2005_wet_01_100 & $1(0.0047)$ & 100 & M2005 \\
M2005_wet_03_100 & $3(0.0140)$ & $\ldots$ & M2005 \\
.. & $80(0.3741)$ & 100 & $\ldots$ \\
M2005_wet_80_100 & & M2005 \\
\hline
\end{tabular}


(a)

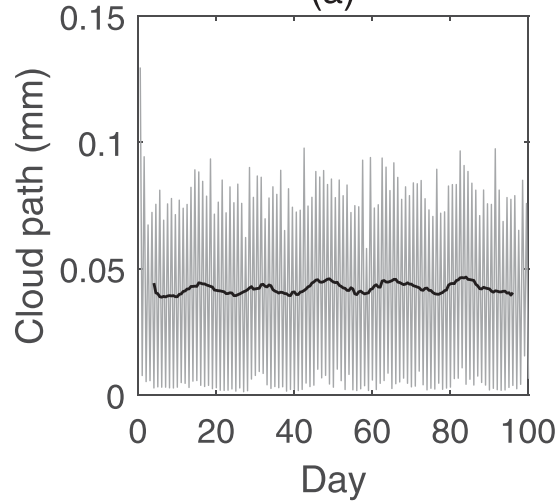

(d)

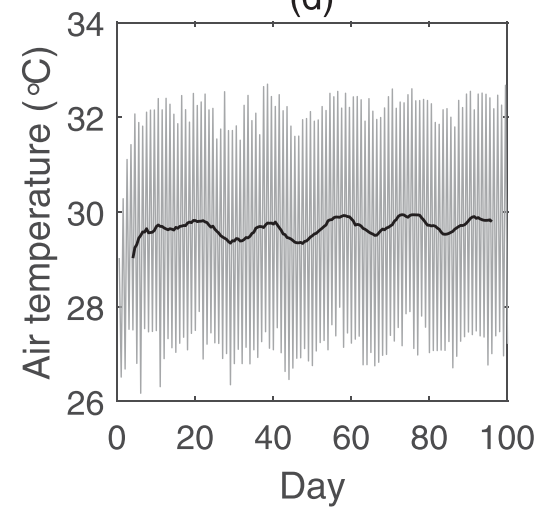

(b)

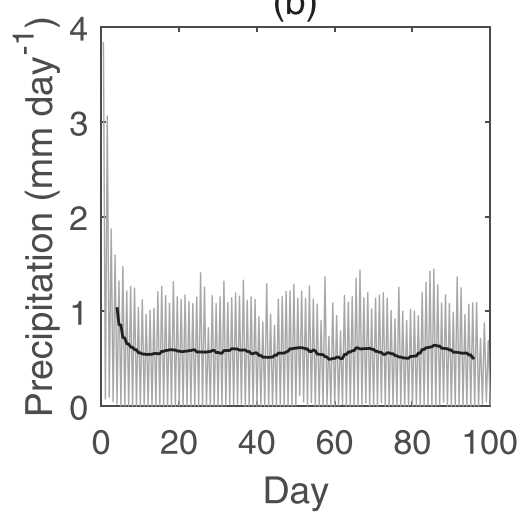

(e)

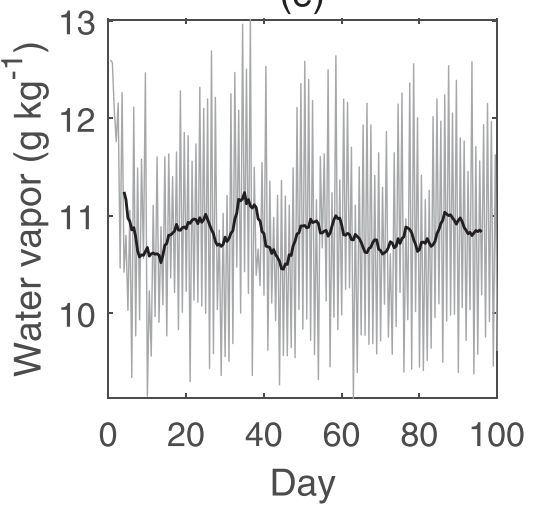

(c)

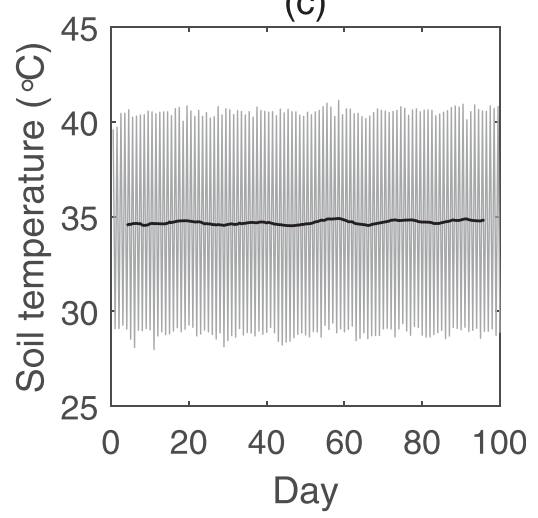

(f)

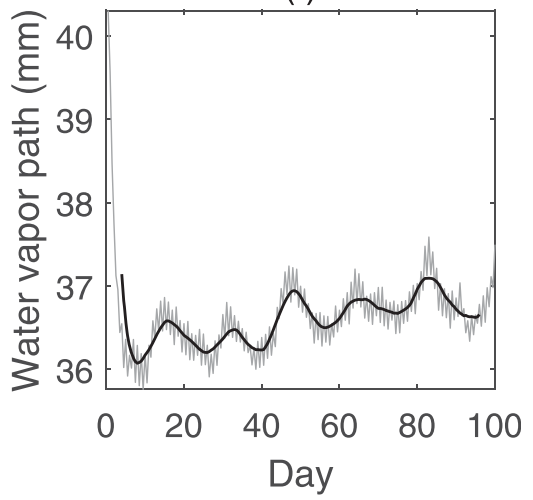

FIG. 2. Temporal evolution of (a) cloud path, (b) precipitation rate, (c) top soil temperature, (d) air temperature at the lowest grid (15 $\mathrm{m}$ above the land surface), (e) water vapor at the lowest grid, and (f) water vapor path in the first 100 days of the experiment wet_01_100. The black lines denote the 7-day moving average.

Previous studies (e.g., CH18) have used a prescribed sounding as an initial condition. Since the results are quite sensitive to the choice of sounding, we would like to avoid this approach. Instead, we allow the atmosphere to equilibrate to the land surface state, and then use the equilibrated atmospheric sounding as an initial condition for the simulation. Specifically, given the soil moisture of a wet patch $\phi_{\text {wet }}\left(\mathrm{m}^{3} \mathrm{~m}^{-3}\right)$ and a dry patch $\phi_{\mathrm{dry}}$, a radiativeconvective equilibrium (RCE) simulation is run with fixed, noninteractive soil moisture for 100 days to reach a quasi-equilibrium state. Radiative-convective equilibrium over land has been treated as an idealized model of the Sahel in previous work (Hohenegger and Stevens 2018). If soil moisture was not held fixed in these simulations, the soil moisture field would evolve to a more homogeneous distribution rather than the specified heterogeneous binary structure we aim to study (Fig. 1). After achieving a quasi-equilibrium state, the spatially varying atmospheric profile from the 100-day simulation is used as the initial condition (starting at 0600 local time) for the atmosphere in an additional 1-day simulation, in which soil moisture is no longer fixed, and allowed to freely interact with the atmosphere; these 1-day simulations are the focus of this study. Our approach results in an initial atmospheric profile that is sensitive to soil moisture, as might be expected in an inland continental environment. A range of experiments are run using different values of $\phi_{\text {dry }}$ and $\phi_{\text {wet }}$ and also using two different microphysics schemes (Table 1).
Why not run the simulation to equilibrium over a completely dry land surface, and then add the wet patch for the 1-day interactive simulation? This approach would arguably be closer to what happens in the real world when a wet patch appears rapidly in response to rainfall. We found that the atmosphere becomes unrealistically hot and dry in such simulations, since in RCE there is no convergence of moisture from the ocean or divergence of heat. Including the wet patch in the 100-day simulation to equilibrium mitigates this problem by including a water source that is functionally similar to the ocean, resulting in equilibrated atmospheric temperatures and humidities that are more realistic.

The 100-day time series of domain-averaged cloud path, precipitation rate, top soil temperature, the lowest-grid $(15 \mathrm{~m}$ above ground) air temperature, the lowest-grid water vapor, and water vapor path are presented for the experiment wet_ 01_100 (Fig. 2), all of which appear to reach an approximately quasi-steady state in 100 days. Most importantly, there is a large adjustment in the first 5-10 days, in which the system transitions away from its arbitrary initial conditions. The precipitation rate around $0.6 \mathrm{~mm} \mathrm{day}^{-1}$ and near-surface air temperature around $30^{\circ}$ are broadly consistent with conditions in the Sahel region (Almazroui et al. 2020). We note that there are intraseasonal oscillations of precipitation as well as water vapor path at the end of the 100-day simulations (Fig. 2). Similar intraseasonal oscillations of precipitation and water 
(a)

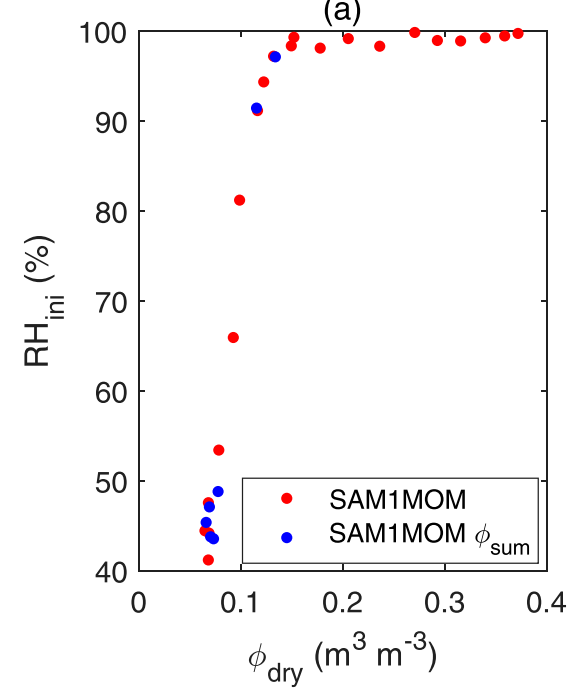

(b)

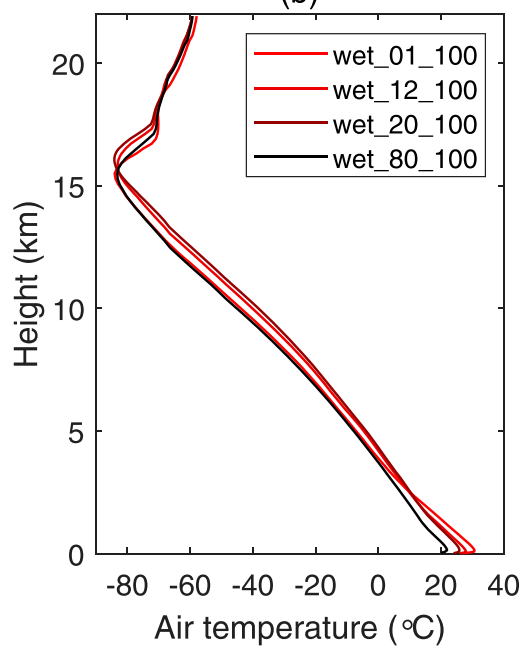

(c)

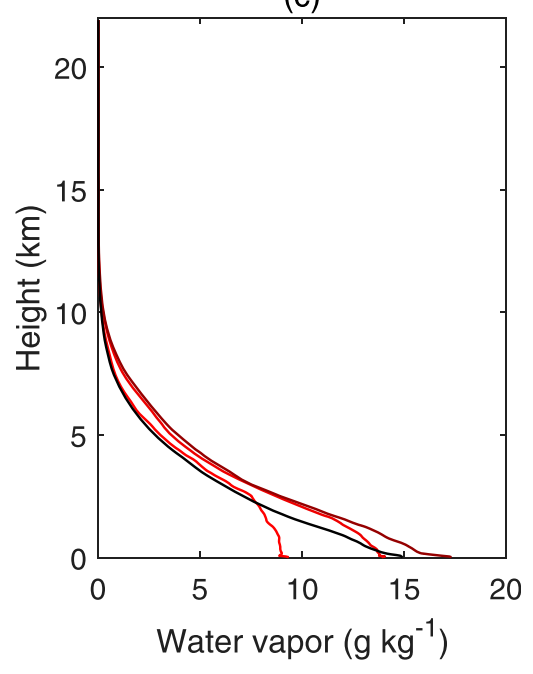

FIG. 3. (a) The initial (0600 LT) relative humidity $\left(\mathrm{RH}_{\text {ini }}\right)$ at the lowest grid averaged over the whole domain plotted against mean $\phi_{\text {dry }}$ in the 1-day simulation. The red dots denote the first 100-day simulations with varying $\phi_{\text {dry }}$ but fixed $\phi_{\text {wet }}$, while the blue dots denote simulations with fixed sum of $\phi_{\text {dry }}$ and $\phi_{\text {wet }}$. (b) Initial (0600 LT) vertical profiles in the 1-day simulations of air temperature and (c) water vapor averaged over the whole domain in the experiments wet_01_100, wet_12_100, wet_20_100, and wet_80_100.

vapor path have been reported in atmospheric observations over tropical oceans (Bretherton et al. 2004). Interactions between radiation, cumulus convection, and surface fluxes of sensible heat and moisture have been shown to be sufficient to produce such oscillations over oceans (Hu and Randall 1994). It is likely that similar processes generate oscillations in our simulations over land, although a full investigation of these processes is beyond the scope of this study.

The initial atmospheric profiles used in our simulations vary substantially in response to varying soil moisture. Soil moisture in the dry patch evolves with time in the 1-day simulation but the daily average of $\phi_{\text {dry }}$ typically remains similar to its initial value except when the initial $\phi_{\text {dry }}$ is close to 0 , as in CH18. The initial relative humidity $\left(\mathrm{RH}_{\mathrm{ini}}\right)$ at the lowest grid cell $(15 \mathrm{~m}$ above the ground) averaged over the whole domain is highly sensitive to the daily averaged $\phi_{\text {dry }}$ when $\phi_{\text {dry }} \leq 0.13 \mathrm{~m}^{3} \mathrm{~m}^{-3}$ (Fig. 3a). The value $0.13 \mathrm{~m}^{3} \mathrm{~m}^{-3}$ of soil moisture likely depends on soil type and the soil moisture resistance function used in the land surface model. Note that Fig. 3a shows 0600 LT values of RH, not daily mean values. The diurnal cycle of $\mathrm{RH}$ peaks around sunrise, explaining the relatively high values in Fig. 3a. Daily mean values of RH in our simulations (not shown) are lower than those in Fig. 3a, and are broadly consistent with real-world values in dry regions such as the Sahel. The 100-day simulations with varying $\phi_{\text {dry }}$ but fixed $\phi_{\text {wet }}$ produce similar atmospheric conditions as those simulations with fixed total water content (sum of $\phi_{\text {dry }}$ and $\phi_{\text {wet }}$ ); thus, we focus our analysis on simulations in which $\phi_{\text {dry }}$ is varied rather than $\phi_{\mathrm{dry}}+\phi_{\mathrm{wet}}$. As expected, a wide variety of initial atmospheric conditions have been generated by the 100-day simulations with fixed soil moisture (Figs. 3b,c). The air temperature near the surface (lower than $1 \mathrm{~km}$ in height) averaged over the whole domain is higher in experiments with smaller $\phi_{\text {dry }}$ (Fig. 3b). The specific humidity of the lower atmosphere is also very sensitive to $\phi_{\mathrm{dry}}$, although the response is not monotonic: the specific humidity near the surface peaks in the experiment wet_20_100 (Fig. 3c). This is likely due to the competing effects of surface evaporation and moisture convergence over the dry patch, which are discussed in more detail below. Therefore, our approach builds on recent work (CH18), which used two initial atmospheric soundings and which noted that the results were sensitive to the choice of initial sounding.

\section{Results}

\section{a. Evolution of climate variables}

In this section, we focus in detail on outputs from one of the simulations listed in Table 1 (wet_01_100, Fig. 4). Clouds (Fig. 4a) and precipitation (Fig. 4b) start to form mainly over the dry patch around $0900 \mathrm{LT}$, which is consistent with the observed precipitation preferentially forming over the dry patch in previous studies (Avissar and Liu 1996; CH18). The locations of large cloud path and precipitation in Figs. $4 \mathrm{a}$ and $4 \mathrm{~b}$ are close to where the convergence of $y$-averaged zonal wind $(U)$ at a height of $135 \mathrm{~m}$ above the surface exists in Fig. 4e. Near the center of the domain, the $y$-averaged zonal wind blows from the wet patch to the dry patch at a height of $135 \mathrm{~m}$ (Fig. 4e) starting around $0900 \mathrm{LT}$, which is an indicator of the mesoscale circulation due to differential heating. In the beginning of the 1-day simulation, the $y$-averaged air temperature at the lowest grid ( $15 \mathrm{~m}$ above the ground) over the dry patch is about $5^{\circ} \mathrm{C}$ higher than that over the wet patch (Fig. 4c) since the latent heat flux is limited by available soil moisture in the dry patch. The $y$-averaged water vapor concentration at the lowest grid (Fig. 4d) over the dry patch is lower than that over the wet patch. During the 1-day simulation, the differences in near-surface temperature and water 


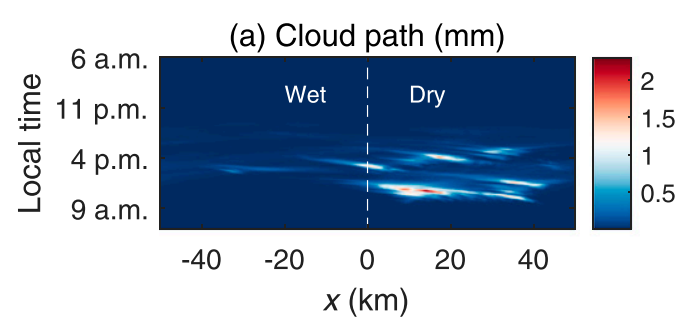

(c) Air temperature $\left({ }^{\circ} \mathrm{C}\right)$

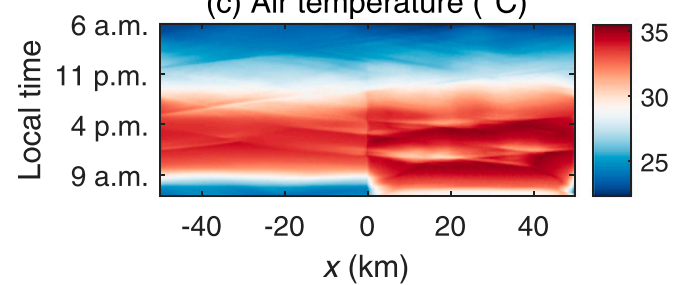

(e) $\cup\left(\mathrm{m} \mathrm{s}^{-1}\right)$

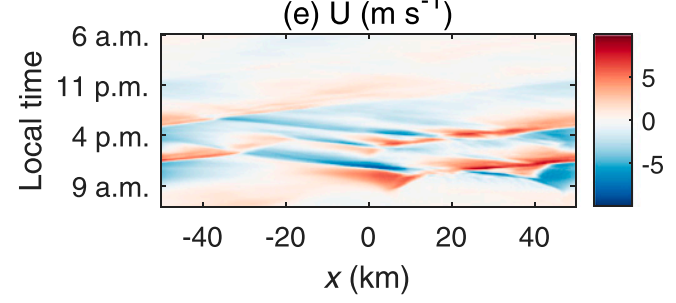

(b) Precipitation $\left(\mathrm{mm} \mathrm{day}^{-1}\right)$

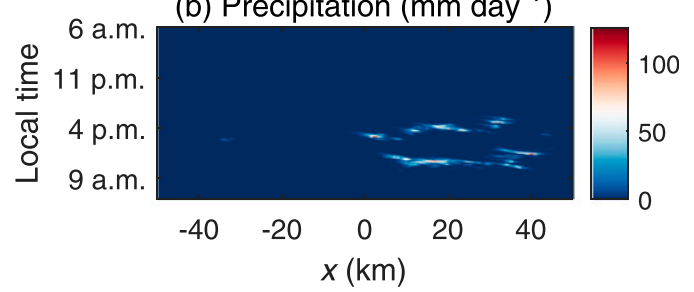

(d) Water vapor $\left(\mathrm{g} \mathrm{kg}^{-1}\right)$

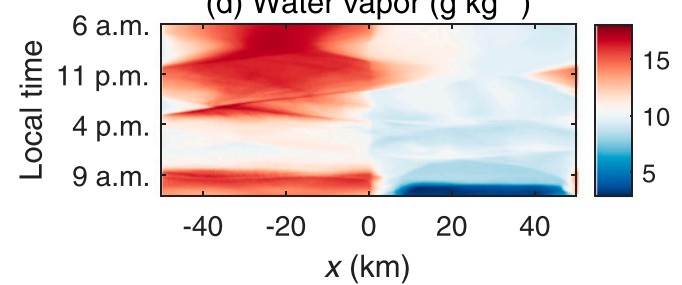

FIG. 4. Temporal evolution of (a) cloud path, (b) precipitation rate, (c) air temperature at the lowest grid, (d) water vapor at the lowest grid, and (e) $y$-averaged zonal wind $(U)$ at a height of $135 \mathrm{~m}$ above the surface in the additional 1-day simulation of the experiment wet_01_100. The $x$ axis denotes the distance from domain center in the $x$ direction, and the $y$ axis denotes local time. The white dashed line in (a) denotes the center of the domain.

vapor between the two patches are reduced due to the interactive soil moisture setup.

At 1000 local time, the near-surface ( $15 \mathrm{~m}$ above the surface) temperature over the dry patch is about $2.7 \mathrm{~K}$ higher than that over the wet patch (Fig. 5), which is caused by the difference in sensible heat flux $\left(270 \mathrm{~W} \mathrm{~m}^{-2}\right)$. This temperature difference leads to a pressure difference of approximately $50 \mathrm{~Pa}$ near the surface, consistent with a thermally driven circulation (Segal and Arritt 1992). Similarly to CH18, moist air moves toward the dry patch from the surface up to $1 \mathrm{~km}$ in the lower part of the circulation, while a return flow toward the wet patch is observed between 1 and $4 \mathrm{~km}$, as shown by the wind vectors in Fig. 5. Consistent with Fig. 4b, this mesoscale circulation leads to precipitation preferentially over the dry patch (Cioni and Hohenegger 2017).

The accumulated domain-averaged evaporation over the wet patch is around $6 \mathrm{~mm}$ (Fig. 6) in the 1-day experiment wet_01_100, while that over the dry patch is close to 0 . Consistent with Fig. 4b, the accumulated domain-averaged precipitation over the dry patch is around $1 \mathrm{~mm}$, while there is almost no precipitation over the wet patch. To identify the contribution of nonlocal moisture to the water balance, we compute a horizontal convergence term for a control volume over the dry patch as follows,

$$
A_{\mathrm{dry}}=\frac{\partial W_{\mathrm{dry}}}{\partial t}-E_{\mathrm{dry}}+P_{\mathrm{dry}}
$$

where $W_{\text {dry }}$ (unit: $\mathrm{mm}$ ) is column-integrated total moisture including vapor, liquid and solid water in the air over the dry patch, $E_{\text {dry }}$ (unit: $\mathrm{mm} \mathrm{d}^{-1}$ ) and $P_{\text {dry }}$ (unit: $\mathrm{mm} \mathrm{d}^{-1}$ ) are averaged evaporation and precipitation rates over the dry patch, respectively, and $A_{\mathrm{dry}}$ (unit: $\mathrm{mm} \mathrm{d}^{-1}$ ) is the horizontal convergence of water vapor into the dry patch. Since there are two patches in total, we have $A_{\text {dry }}=-A_{\text {wet }}$. The convergence term $A_{\text {dry }}$ is larger than the evaporation term $E_{\text {dry }}$ (Fig. 6b); thus, the major source of precipitation over the dry patch is convergence of moisture from the wet patch transported by the mesoscale circulation rather than local evaporation. Such dominant convergence effects were also reported in previous numerical simulations (Schär et al. 1999; CH18). In addition, $P_{\text {dry }}$ is smaller than the sum of $E_{\text {dry }}$ and $A_{\text {dry }}$, implying that the total moisture over the dry patch increases with time in the 1-day experiment.

\section{b. Simulations with varying soil moisture}

After describing the results of one simulation in the previous section, in this section we describe results for the full set of simulations with varying $\phi_{\text {dry }}$. Over the dry patch, the accumulated precipitation in 1 day increases with increasing daily averaged soil moisture in the numerical experiments (Table 1) using both the SAM1MOM and M2005 microphysics schemes when daily averaged $\phi_{\text {dry }}$ is smaller than approximately $0.1 \mathrm{~m}^{3} \mathrm{~m}^{-3}$ (Fig. 7a). The accumulated evaporation increases as soil moisture increases (Fig. 7b) for $\phi_{\text {dry }} \leq 0.2 \mathrm{~m}^{3} \mathrm{~m}^{-3}$. Comparing Figs. $7 \mathrm{~b}$ and $7 \mathrm{c}$, we 


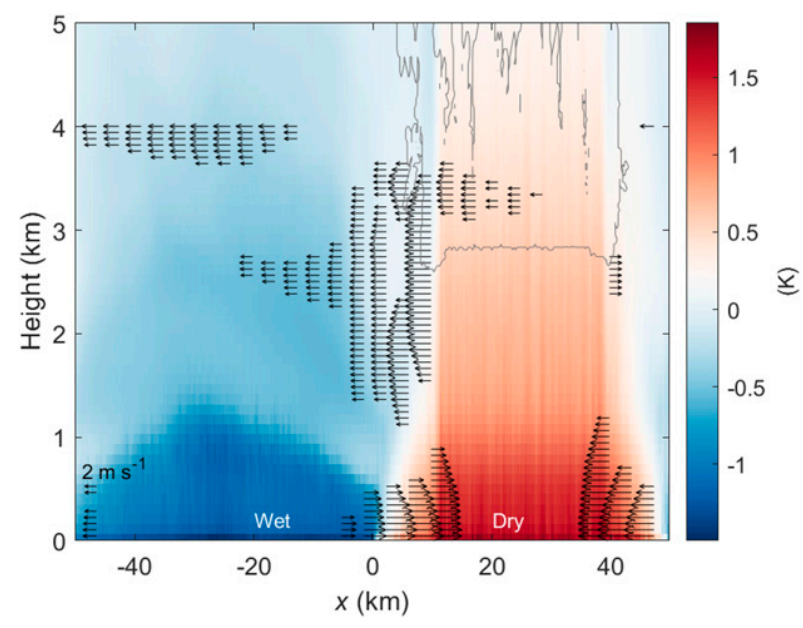

FIG. 5. The $x-z$ diagram at 1000 local time of $y$-averaged quantities for additional 1-day simulation of the experiment wet_01_100. The color contours denote temperature anomaly. The black arrows denote zonal velocity with absolute values not less than $2 \mathrm{~m} \mathrm{~s}^{-1}$, and the text " $2 \mathrm{~m} \mathrm{~s}^{-1}$ " in the bottom left of the figure denotes the velocity of the arrow below. The gray isolines denote nonprecipitating cloud ice and water equal to $10^{-5} \mathrm{~g} \mathrm{~kg}^{-1}$. The $x$ axis denotes the distance from domain center in $x$ direction.

find that convergence is larger than evaporation when $\phi_{\text {dry }} \leq$ $0.1 \mathrm{~m}^{3} \mathrm{~m}^{-3}$, implying that the mesoscale circulation plays a more important role than local evaporation in determining precipitation, at least when $\phi_{\text {dry }}$ is particularly small.

Across simulations, accumulated convergence generally decreases with increasing soil moisture $\phi_{\text {dry }}$ (Fig. 7c), as in $\mathrm{CH} 18$. Increasing $\phi_{\text {dry }}$ reduces the sensible heat flux in the dry patch and thus reduces the heating differential driving the mesoscale circulation. There is some variability around the first-order decreasing relation between accumulated convergence and $\phi_{\text {dry }}$ : for example, accumulated convergence increases with increasing soil moisture when $\phi_{\text {dry }} \leq 0.1 \mathrm{~m}^{3} \mathrm{~m}^{-3}$ in simulations using the microphysics scheme M2005 but not in simulations using SAM1MOM (Fig. 7c). To investigate the possible role of internal variability, for a subset of simulations, we generated a small ensemble of simulations by modifying the initial atmospheric sounding. Specifically, to generate ensembles for the 1-day simulation with interactive soil moisture for a given $\phi_{\text {dry }}$, the initial atmospheric profile was chosen to be the atmospheric profile on a day between the 96th and 99th day of the simulation with fixed soil moisture rather than the 100th day. The results of the ensemble simulations (not shown) were very similar to the results presented in Fig. 7, implying that internal variability is unlikely to be the dominant source of scatter around the decreasing relation in Fig. 7c.

How efficiently does the atmosphere overlying the dry patch convert water inflows $\left(E_{\text {dry }}, A_{\text {dry }}\right)$ into precipitation $\left(P_{\text {dry }}\right)$ ? Similarly to previous studies (Schär et al. 1999; CH18), we define a "large-scale" precipitation efficiency (e.g., Sui et al. 2007) as

$$
\eta_{\mathrm{dry}}=\frac{P_{\mathrm{dry}}}{E_{\mathrm{dry}}+A_{\mathrm{dry}}} .
$$

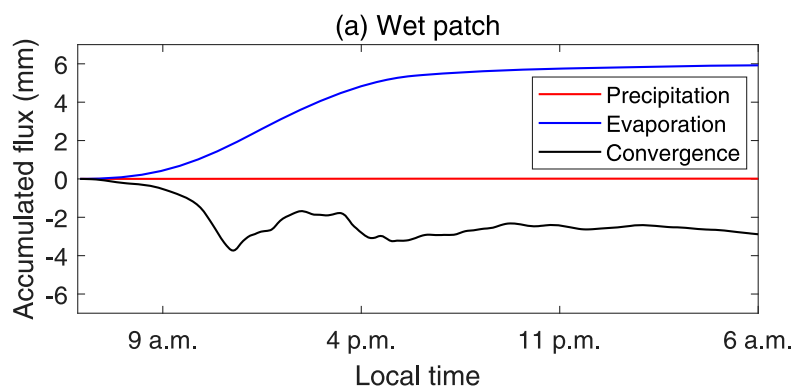

(b) Dry patch

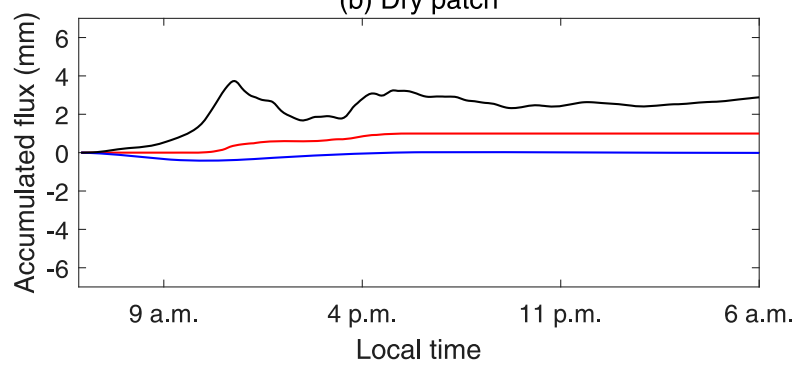

FIG. 6. Accumulated precipitation, evaporation, and convergence over the (a) wet and (b) dry patches in the additional 1-day simulation of the experiment wet_01_100.

At steady state over the dry patch, $\eta_{\text {dry }}=1$, by definition. However, for the transient 1 -day simulations we consider, $\eta_{\text {dry }}$ is typically less than one, as part of the inflows to the atmospheric control volume contribute to moistening the atmosphere, without contributing to precipitation. The value of $\eta_{\text {dry }}$ increases with increasing soil moisture (Fig. $7 d$ ) for $\phi_{\text {dry }} \leq 0.1 \mathrm{~m}^{3} \mathrm{~m}^{-3}$ in both the SAM1MOM and M2005 experiments.

Precipitation over the dry patch is more sensitive to changes in large-scale precipitation efficiency than changes in moisture inputs (evaporation and convergence from the mesoscale circulation), at least when $\phi_{\text {dry }} \leq 0.1 \mathrm{~m}^{3} \mathrm{~m}^{-3}$. The precipitation sensitivity to soil moisture can be written as

$$
\partial_{\phi} P_{\mathrm{dry}}=\partial_{\phi} \eta_{\mathrm{dry}}\left(E_{\mathrm{dry}}+A_{\mathrm{dry}}\right)+\eta_{\mathrm{dry}}\left(\partial_{\phi} E_{\mathrm{dry}}+\partial_{\phi} A_{\mathrm{dry}}\right),
$$

where the first term on the right is the contribution from the large-scale precipitation efficiency sensitivity to soil moisture, and the second term is the contribution from evaporation and convergence sensitivity to soil moisture. Focusing on conditions in which precipitation is most sensitive to soil moisture $\left(0.065 \leq \phi_{\text {dry }} \leq 0.115 \mathrm{~m}^{3} \mathrm{~m}^{-3}\right)$ in experiments using the microphysics scheme SAM1MOM, the precipitation sensitivity due to changes in large-scale precipitation efficiency is $61 \%$ of the total precipitation sensitivity. Similarly, when $0.056 \leq$ $\phi_{\text {dry }} \leq 0.101 \mathrm{~m}^{3} \mathrm{~m}^{-3}$ in experiments using the microphysics scheme M2005, the precipitation sensitivity due to changes in large-scale precipitation efficiency is $87 \%$ of the total precipitation sensitivity. Therefore, the large-scale precipitation efficiency sensitivity to soil moisture is the main factor determining the soil moisture-precipitation relation, at least under the driest conditions in which precipitation is most sensitive to soil moisture. 
(a)

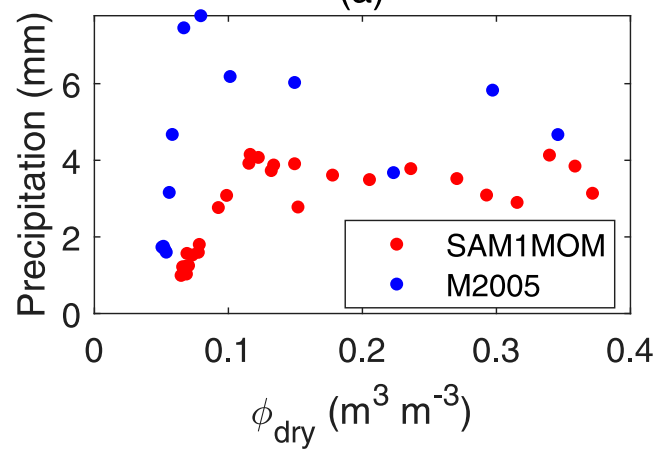

(c)

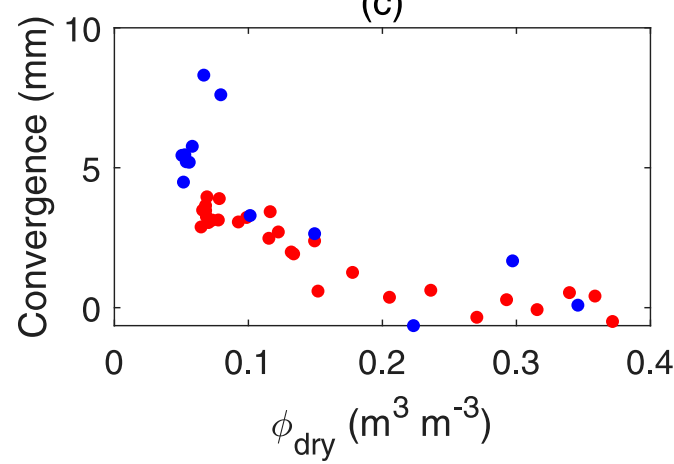

(b)

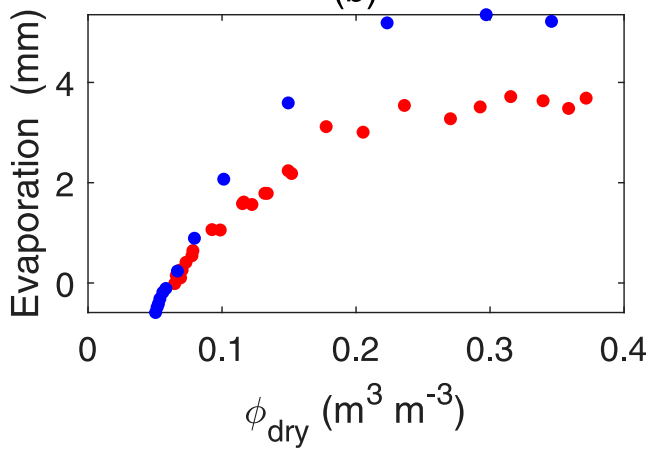

(d)

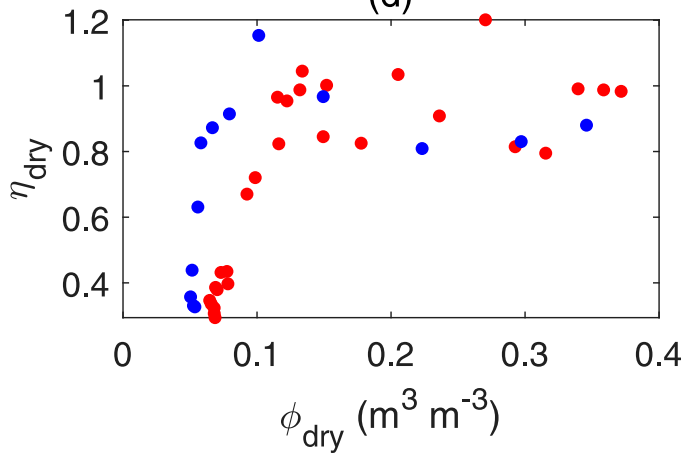

FIG. 7. (a) Accumulated precipitation, (b) evaporation, (c) convergence, and (d) large-scale precipitation efficiency $\eta_{\text {dry }}$ over the dry patch in the additional 1-day simulation of the experiments. The red dots denote experiments using the microphysics scheme SAM1MOM, and the blue dots denote experiments using the microphysics scheme M2005.

\section{c. Soil moisture controls on microphysical precipitation efficiency}

How does soil moisture control the large-scale precipitation efficiency? A mechanism proposed for homogeneous surfaces by Schär et al. (1999), based on the boundary layer moist enthalpy budget, does not easily translate to the heterogeneous case, in which moisture convergence radically alters the sensitivity of boundary layer moist enthalpy to soil moisture. Another explanation based on the microphysical conversion efficiency given in Cioni and Hohenegger (2017) more readily generalizes to the heterogeneous case; however, as we will show, this mechanism does not dominate in our simulations due to the introduced dependency of the initial atmospheric profile on the underlying soil moisture of the dry patch. In this section, we show that soil moisture primarily controls largescale precipitation efficiency in our simulations by impacting precipitation reevaporation.

The "microphysical" precipitation efficiency $\epsilon$ is defined as (Sui et al. 2007; Lutsko and Cronin 2018)

$$
\epsilon=\frac{P}{C}
$$

where $P$ is surface precipitation rate (unit: $\mathrm{kg} \mathrm{m}^{-2} \mathrm{~s}^{-1}$ ) and $C$ is column-integrated condensation rate (unit: $\mathrm{kg} \mathrm{m}^{-2} \mathrm{~s}^{-1}$ ). Although the definitions of large-scale precipitation efficiency $\eta_{\text {dry }}$ and microphysical efficiency $\epsilon$ are different, they are typically correlated (Sui et al. 2007). To understand variations in microphysical precipitation efficiency, we use the decomposition proposed by Lutsko and Cronin (2018), in which microphysical precipitation efficiency is decomposed into a "conversion efficiency" (the proportion of cloud condensate converted to precipitation) and a "sedimentation efficiency" (the proportion of precipitation that avoids reevaporation while falling through the atmosphere and arrives at the land surface). Specifically,

$$
\epsilon=\alpha(1-\beta),
$$

where $\alpha$ is the conversion efficiency and is computed as

$$
\alpha=\frac{P+E_{p}}{C},
$$

where $E_{p}$ (unit: $\mathrm{kg} \mathrm{m}^{-2} \mathrm{~s}^{-1}$ ) is the column-integrated sink of precipitation due to reevaporation, and $(1-\beta)$ is the sedimentation efficiency and is computed as

$$
1-\beta=\frac{P}{P+E_{p}} .
$$

The microphysical precipitation efficiency $\epsilon_{\mathrm{dry}}$, conversion efficiency $\alpha_{\text {dry }}$ and sedimentation efficiency $\left(1-\beta_{\text {dry }}\right)$ over the dry patch are plotted against daily averaged $\phi_{\text {dry }}$ and nearsurface $\mathrm{RH}_{\mathrm{dry}}$ across various 1-day simulations (Fig. 8). The 
(a)

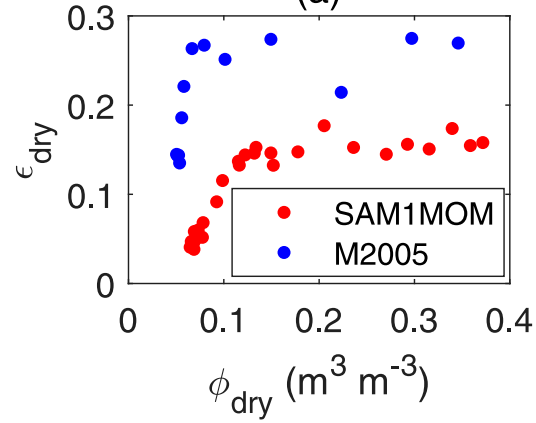

(d)

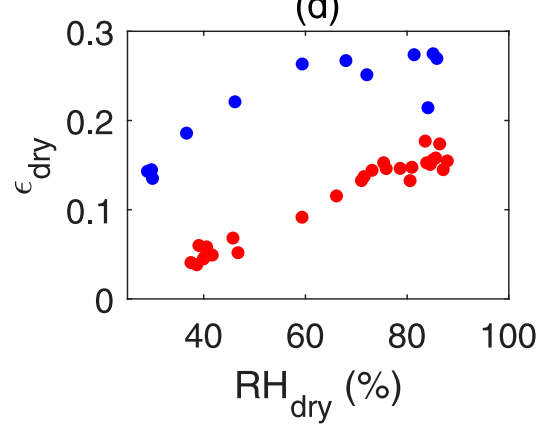

(b)

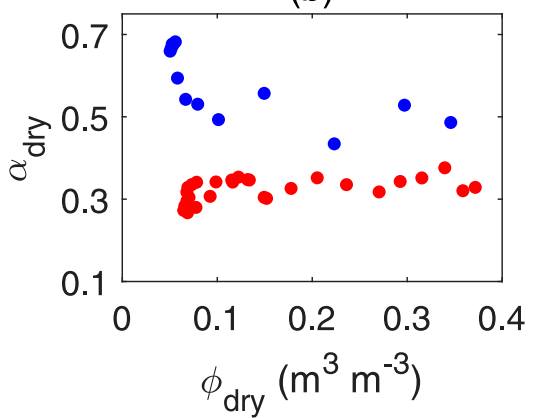

(e)

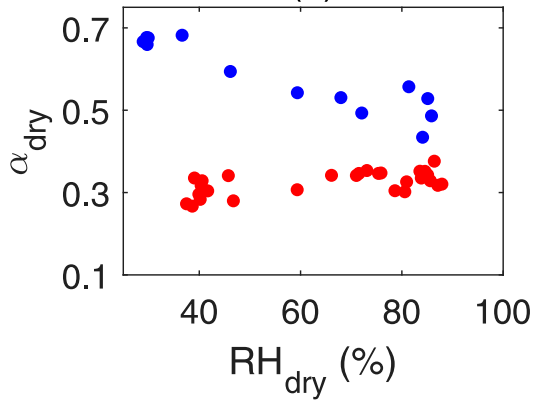

(c)

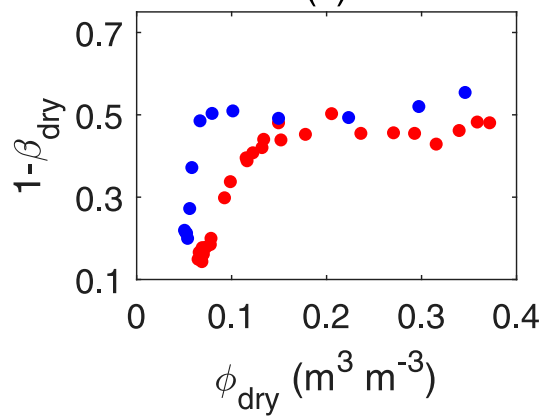

(f)

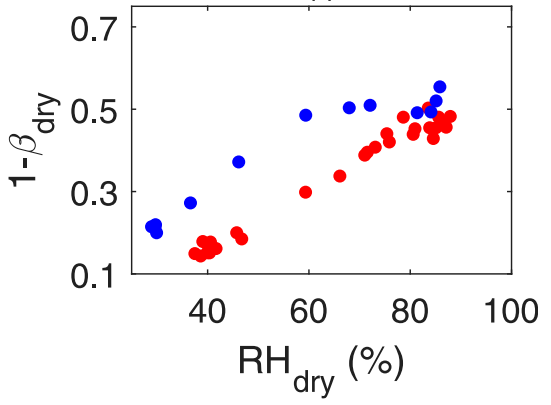

FIG. 8. The relation between microphysical precipitation efficiency $\left(\epsilon_{\text {dry }}\right)$, conversion efficiency $\left(\alpha_{\text {dry }}\right)$, sedimentation efficiency $\left(1-\beta_{\mathrm{dry}}\right)$, and soil moisture $\left(\phi_{\mathrm{dry}}\right)$ and relative humidity $\left(\mathrm{RH}_{\mathrm{dry}}\right)$ at the atmospheric grid cell nearest the land surface. The microphysics schemes SAM1MOM and M2005 are used.

microphysical precipitation efficiency $\epsilon_{\mathrm{dry}}$ increases with increasing soil moisture (Fig. 8) when $\phi_{\text {dry }} \leq 0.15 \mathrm{~m}^{3} \mathrm{~m}^{-3}$ in SAM1MOM simulations (or when $\phi_{\text {dry }} \leq 0.1 \mathrm{~m}^{3} \mathrm{~m}^{-3}$ in $\mathrm{M} 2005$ simulations) in a similar way to the large-scale precipitation efficiency $\eta_{\text {dry }}$ (Fig. 7). Thus, the two precipitation efficiencies are correlated in our simulations, as found previously (Sui et al. 2007). The conversion efficiency $\alpha_{\text {dry }}$ increases with $\phi_{\text {dry }}$ in SAM1MOM simulations but decreases in M2005 simulations when $\alpha_{\text {dry }} \leq 0.1 \mathrm{~m}^{3} \mathrm{~m}^{-3}$. The sensitivity of $\alpha_{\text {dry }}$ to $\phi_{\text {dry }}$ is low when $\phi_{\text {dry }} \geq 0.1 \mathrm{~m}^{3} \mathrm{~m}^{-3}$, for both microphysics schemes. The sedimentation efficiency $\left(1-\beta_{\text {dry }}\right)$ exhibits a qualitatively similar relation to $\phi_{\mathrm{dry}}$ as $\epsilon_{\mathrm{dry}}$ : increasing with increasing $\phi_{\mathrm{dry}}$ up to a threshold before becoming relatively insensitive to $\phi_{\mathrm{dry}}$ above the threshold (Fig. 8c). Therefore, the sedimentation efficiency is the dominant control on microphysical precipitation efficiency in our simulations rather than the conversion efficiency (the mechanism proposed by Cioni and Hohenegger 2017). In addition, the soil moisture threshold at which precipitation stops increasing with increasing soil moisture $\phi_{\mathrm{dry}}=$ $0.13 \mathrm{~m}^{3} \mathrm{~m}^{-3}$ (Fig. 7a) is close to the equivalent threshold for $\eta_{\text {dry }}$ (Fig. 7 d), $\epsilon_{\text {dry }}$ (Fig. 8a), and $1-\beta_{\text {dry }}$ (Fig. 8c) but deviates more from that of evaporation (Fig. 7b) and convergence (Fig. 7c). This further suggests that precipitation efficiency plays an important role in controlling precipitation.

Both $\epsilon_{\text {dry }}$ and $1-\beta_{\text {dry }}$ (Figs. 8d,f) are linearly related to near-surface relative humidity ( $15 \mathrm{~m}$ above the ground) when $\mathrm{RH}_{\mathrm{dry}} \leq 80 \%$, thus emphasizing the dominant role of sedimentation efficiency in determining $\epsilon_{\text {dry }}$. The value of $\alpha_{\text {dry }}$ increases with increasing near-surface relative humidity in
SAM1MOM simulations but decreases in M2005 simulations (Fig. 8e), suggesting that $\alpha_{\text {dry }}$ varies in different microphysics schemes.

\section{Discussion}

\section{a. Conceptual model}

In this section, we propose a simple conceptual model that highlights the main physical processes in our simulations. This model is not intended for prediction; rather, it is a tool for understanding. It consists of three components: 1) a "bucket model" representation of evaporation, 2) a land-sea breeze circulation model of convergence, and 3) a model of precipitation efficiency based on the Lutsko and Cronin (2018) scaling of sedimentation efficiency with relative humidity. The first two components are identical to those used in $\mathrm{CH} 18$, but the addition of the third component to the conceptual model is new.

First, a "bucket model" is used for evaporation (Manabe 1969), as in CH18. Specifically,

$$
E_{\mathrm{dry}}\left(\phi_{\mathrm{dry}}\right)=A R_{n} \times \begin{cases}0, & \text { for } \phi_{\mathrm{dry}}<\phi_{\mathrm{wp}} \\ \frac{\phi_{\mathrm{dry}}-\phi_{\mathrm{wp}}}{\phi_{\mathrm{fc}}-\phi_{\mathrm{wp}}}, & \text { for } \phi_{\mathrm{wp}} \leq \phi_{\mathrm{dry}} \leq \phi_{\mathrm{fc}} \\ 1, & \text { for } \phi_{\mathrm{dry}}>\phi_{\mathrm{fc}}\end{cases}
$$

where $\phi_{\mathrm{wp}}$ is the effective "wilting point" soil moisture $\left(\mathrm{m}^{3} \mathrm{~m}^{-3}\right), \phi_{\mathrm{fc}}$ is the effective "field capacity" soil moisture 

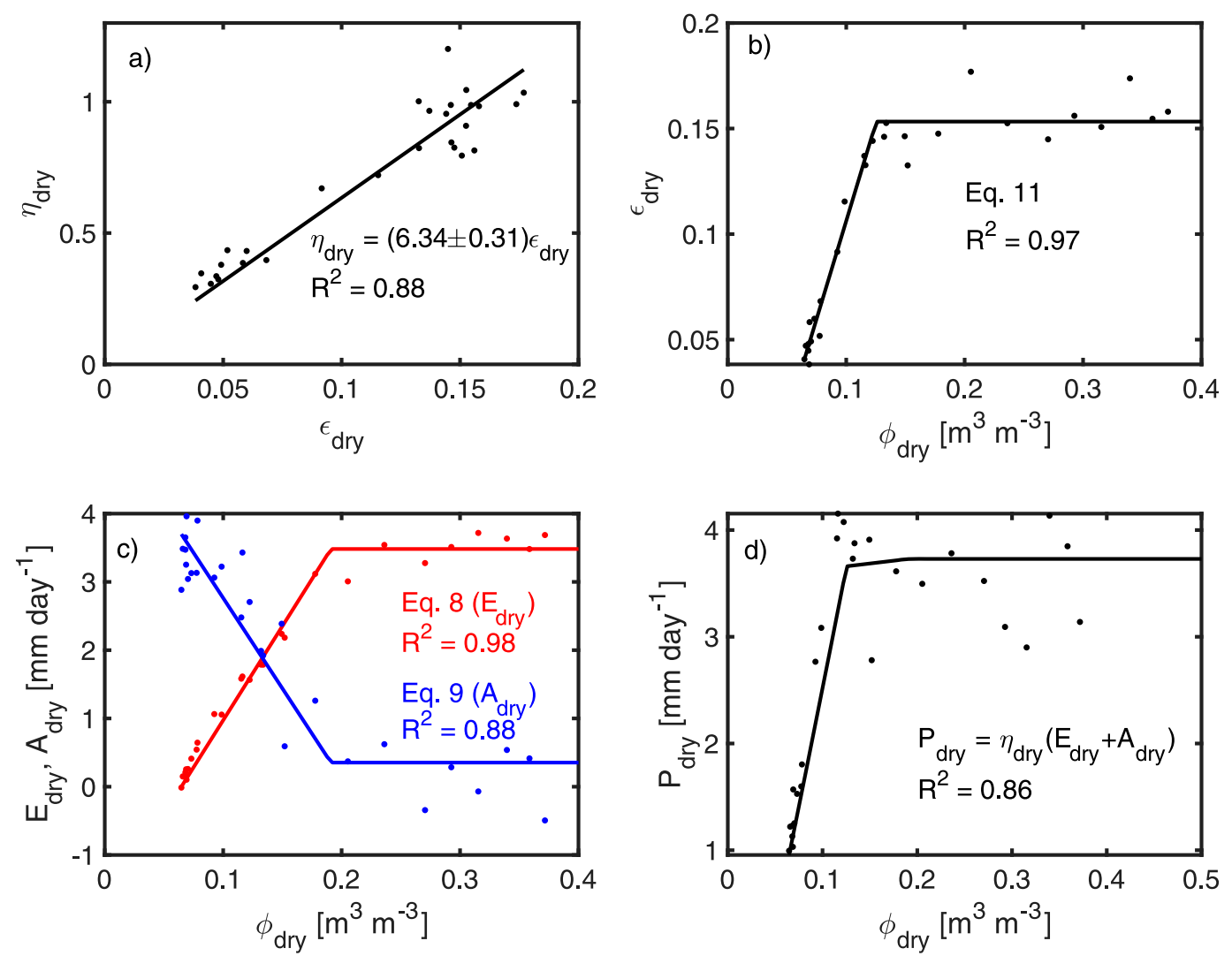

FIG. 9. Conceptual model of $P_{\text {dry }}$. (a) Estimated linear relation between $\epsilon_{\text {dry }}$ and $\eta_{\text {dry }}$. The estimated coefficient includes a confidence interval of two standard errors. (b) Estimated relation between $\phi_{\mathrm{dry}}$ and $\epsilon_{\mathrm{dry}}$, as given in Eq. (11). (c) Estimated relations between $\phi_{\text {dry }}$ and $E_{\text {dry }}$ [red line, Eq. (8)] and $A_{\text {dry }}$ [blue line, Eq. (9)]. (d) Predicted relation between $\phi_{\mathrm{dry}}$ and $P_{\mathrm{dry}}$.

$\left(\mathrm{m}^{3} \mathrm{~m}^{-3}\right), R_{n}$ is net radiation $\left(\mathrm{mm} \mathrm{day}^{-1}\right)$, and $A$ is a dimensionless parameter. The wilting point and field capacity are referred to as "effective" values because the values obtained by fitting Eq. (8) to observations do not necessarily correspond to values obtained from more direct estimation methods (Seneviratne et al. 2010). The wilting point is estimated as the minimum simulated equilibrated value of soil moisture in the dry patch: $\phi_{\mathrm{wp}}=0.06 \mathrm{~m}^{3} \mathrm{~m}^{-3}$. The values of "effective" wilting point and field capacity will vary when different soil types and soil moisture resistance functions are used. The model's two other parameters are estimated by fitting Eq. (8) to outputs from the simulations using the SAM1MOM microphysics scheme. The estimated parameters are $A=3.48 \pm 0.12$ and $\phi_{\mathrm{fc}}=0.19 \pm 0.009 \mathrm{~m}^{3} \mathrm{~m}^{-3}$, where given confidence intervals are two standard errors. The model fits the simulation results very well $\left(R^{2}=0.98\right.$, Fig. 9c).

Second, a land-sea breeze circulation model is constructed based on the principle that a stronger heating differential drives a stronger mesoscale circulation, with stronger convergence. Specifically, $A_{\text {dry }} \propto H_{\text {dry }}-H_{\text {wet }}=R_{n \text {,dry }}-R_{n \text {,wet }}+\lambda$ ( $E_{\text {wet }}-E_{\text {dry }}$ ), where the surface energy balance is applied to eliminate dependence on sensible heat fluxes, $\lambda$ is the latent heat of vaporization of water, and ground heat flux is neglected since its contribution is small. In our simulations, $R_{n \text {,dry }}-R_{n \text {,wet }}$ decreases with decreasing soil moisture, and $E_{\text {wet }}$ increases with decreasing soil moisture $\left(\phi_{\text {dry }}\right)$. The former is largely due to greater surface temperatures over the dry patch causing greater outgoing longwave radiation in the dry patch as well as the albedo effects on shortwave radiation; the latter is due to increased vapor pressure deficit over the wet patch caused by low $\phi_{\text {dry. }}$ The soil moisture dependence of these terms approximately cancels out in our simulations, such that $R_{n, \text { dry }}-R_{n \text {,wet }}+$ $\lambda E_{\text {wet }}$ is relatively insensitive to soil moisture. Most of the soil moisture dependence is, therefore, due to $E_{\text {dry. }}$ In our simulations the dependence is adequately represented by

$$
A_{\text {dry }}\left(\phi_{\text {dry }}\right)=B\left[E_{\text {wet } 0}-E_{\text {dry }}\left(\phi_{\text {dry }}\right)\right]
$$

where $B$ (dimensionless) and $E_{\text {wet } 0}$ (denoting $R_{n, \text { dry }}-R_{n \text {,wet }}+$ $\left.\lambda E_{\mathrm{wet}}\right)\left(\mathrm{mm} \mathrm{day}^{-1}\right)$ are fixed parameters. This model is identical to that used in $\mathrm{CH} 18$, although their derivation is different. Fitting this functional form to the simulation outputs results in an adequate fit $\left(R^{2}=0.88\right.$, Fig. 9c), with $B=0.96 \pm 0.14$ and $E_{\mathrm{wet} 0}=3.85 \pm 0.37\left(\mathrm{~mm} \mathrm{day}^{-1}\right)$. If $B \approx 1$, as in our simulations, then adding Eqs. (8) and (9) implies that $A_{\text {dry }}\left(\phi_{\text {dry }}\right)+$ $E_{\text {dry }}\left(\phi_{\text {dry }}\right) \approx E_{\text {wet } 0}$, which is invariant to changes in soil moisture in our conceptual model. This implies that, while $A_{\mathrm{dry}}$ and $E_{\text {dry }}$ are both sensitive to soil moisture, the total supply of 
atmospheric moisture over the dry patch is not, at least to first order. In the simulations with arbitrary initial conditions performed by $\mathrm{CH} 18, B$ deviated considerably from one; as a result, $A_{\text {dry }}+E_{\text {dry }}$ was sensitive to soil moisture in those simulations. We speculate that the fact that $B \approx 1$ in our simulations is not a coincidence but rather a result of allowing the atmosphere to equilibrate to the land surface state.

Third, a simple model of precipitation efficiency as a function of soil moisture is derived. In our simulations, most of the variations in $\epsilon_{\mathrm{dry}}$ with changes in soil moisture are explained by variations in sedimentation efficiency (Fig. 8c) rather than conversion efficiency (Fig. 8b), so we treat $\alpha_{\text {dry }}$ as a constant and focus on $\beta_{\mathrm{dry}}$. Lutsko and Cronin (2018) proposed a simple scaling for the sedimentation efficiency:

$$
\beta \propto \frac{(1-\mathrm{RH}) h}{w},
$$

where $\mathrm{RH}$ is the relative humidity (\%), $h$ is the average height at which precipitation forms $(\mathrm{m}), w$ is the average fall speed $\left(\mathrm{m} \mathrm{s}^{-1}\right)$, and the implied constant of proportionality has units of $\mathrm{s}^{-1}$. If $h / w$ is treated as approximately constant, and the near-surface $\mathrm{RH}$ is treated as a first-order estimate of $\mathrm{RH}$ higher in the atmosphere, then combining Eqs. (10) and (5) results in a linear increasing relation between $\epsilon_{\text {dry }}$ and near-surface $\mathrm{RH}_{\mathrm{dry}}$, just as we observe in our simulations (Fig. 8f). To obtain a model for $\epsilon_{\mathrm{dry}}$ in terms of $\phi_{\mathrm{dry}}$, we simply note that the initial nearsurface relative humidity $\left(\mathrm{RH}_{\mathrm{ini}}\right.$, and consequently $\left.\mathrm{RH}_{\mathrm{dry}}\right)$ can be approximated by an increasing function of $\phi_{\text {dry }}$ in our simulations (Fig. 3). This is qualitatively consistent with results from simple models of an idealized atmospheric boundary layer over land (Betts 2000; McColl et al. 2019) and is explained by the strong dependence of near-surface $\mathrm{RH}$ on surface fluxes (McColl and Rigden 2020; Chen et al. 2021), which in turn are constrained by soil moisture. Since precipitation efficiency can be represented adequately solely as a function of $\mathrm{RH}_{\mathrm{dry}}\left[\epsilon_{\mathrm{dry}}=\right.$ $f\left(\mathrm{RH}_{\text {dry }}\right)$ ], and $\mathrm{RH}_{\text {dry }}$ can be represented adequately solely as a function of soil moisture $\left[\mathrm{RH}_{\mathrm{dry}}=g\left(\phi_{\mathrm{dry}}\right)\right]$, this implies that precipitation efficiency can be modeled reasonably as a function of soil moisture alone $\left[\epsilon_{\mathrm{dry}}=h\left(\phi_{\mathrm{dry}}\right)\right]$. Rather than estimating and combining the functions $f$ and $g$, we simply estimate $h$ directly from simulation outputs. The observed dependence is approximated reasonably by a function of the form

$$
\epsilon_{\mathrm{dry}}\left(\phi_{\mathrm{dry}}\right)= \begin{cases}\epsilon_{\min }, & \text { for } \phi_{\mathrm{dry}}<\phi_{\mathrm{wp}} \\ \epsilon_{\min }+\left(\epsilon_{\max }-\epsilon_{\min }\right) \frac{\phi_{\mathrm{dry}}-\phi_{\mathrm{wp}}}{\phi^{*}-\phi_{\mathrm{wp}}}, & \text { for } \phi_{\mathrm{wp}} \leq \phi_{\mathrm{dry}} \leq \phi^{*} \\ \epsilon_{\max }, & \text { for } \phi_{\mathrm{dry}}>\phi^{*}\end{cases}
$$

where $\epsilon_{\min }$ (dimensionless), $\epsilon_{\max }$ (dimensionless), and $\phi^{*}\left(\mathrm{~m}^{3} \mathrm{~m}^{-3}\right)$ are parameters. This functional form fits simulated values very well $\left(R^{2}=0.97\right.$, Fig. 9b), with the following estimated parameter values: $\epsilon_{\min }=0.041 \pm 0.007, \epsilon_{\max }=0.15 \pm 0.005$, and $\phi^{*}=0.13 \pm 0.007 \mathrm{~m}^{3} \mathrm{~m}^{-3}$. Finally, as noted in previous studies (e.g., Sui et al. 2007), $\epsilon$ and $\eta$ are typically well correlated. In our simulations, they are proportional to one another and are adequately represented by the relation $\eta_{\text {dry }}=(6.34 \pm 0.31) \epsilon_{\text {dry }}$ $\left(R^{2}=0.88\right.$, Fig. 9a).

Combining these elements using the relation $P_{\text {dry }}=$ $\eta_{\mathrm{dry}}\left(A_{\mathrm{dry}}+E_{\mathrm{dry}}\right)$ results in a conceptual model that fits the simulated precipitation values adequately $\left(R^{2}=0.86\right.$, Fig. 9), and particularly well when $\phi_{\text {dry }}$ is low. If our conceptual model had directly fit $\eta_{\text {dry }}=P_{\text {dry }} /\left(A_{\text {dry }}+E_{\text {dry }}\right)$ to $\phi_{\mathrm{dry}}$, then this result would be trivial: a reasonable model fit would be expected even in the absence of any soil moisture impact on $\epsilon_{\mathrm{dry}}$. This is why we separately relate $\eta_{\mathrm{dry}}$ to $\epsilon_{\mathrm{dry}}$ (Fig. 9a), and $\epsilon_{\text {dry }}$ to $\phi_{\text {dry }}$ (Fig. 9b), which clearly demonstrates the significant impact of soil moisture on $\epsilon_{\mathrm{dry}}$. The focus of this model is on precipitation caused by heterogeneous soil moisture, so it naturally becomes less applicable as $\phi_{\mathrm{dry}}$ increases toward $\phi_{\mathrm{wet}}$; in our simulations, for $\phi_{\mathrm{dry}}>$ $\phi_{\mathrm{fc}}=0.19 \mathrm{~m}^{3} \mathrm{~m}^{-3}$, soil moisture no longer limits latent heat flux and other physical processes regulate surface fluxes and precipitation.

A summary of the most important physical mechanisms determining precipitation in our simulations is given in
Fig. 10. As $\phi_{\text {dry }} \rightarrow 0$ (Fig. 10a), the heating differential between wet and dry patches increases, intensifying the mesoscale circulation. Convergence of moisture over the dry patch increases, but evaporation within the dry patch decreases. In contrast, as $\phi_{\text {dry }} \rightarrow \phi_{\text {wet }}$ (Fig. 10b), the heating differential between wet and dry patches decreases, weakening the mesoscale circulation. Convergence of moisture over the dry patch decreases, but evaporation within the dry patch increases. In both cases, changes in convergence and evaporation with soil moisture approximately cancel out, such that the total supply of atmospheric moisture $\left(A_{\mathrm{dry}}+E_{\mathrm{dry}}\right)$ is relatively insensitive to changes in $\phi_{\mathrm{dry}}$. Therefore, changes in atmospheric moisture supply play a minor role in the observed relation between $P_{\text {dry }}$ and $\phi_{\text {dry }}$. Instead, the relation is mainly determined by higher reevaporation of precipitation over drier soils. Since the atmosphere is allowed to equilibrate with the land surface in our simulations, a drier land surface leads to a drier atmosphere, in which $\mathrm{RH}$ is lower (Fig. 3), sedimentation efficiency is lower (Figs. 8c,f), and a smaller proportion of precipitation avoids reevaporation on its way to the land surface. The result is declining precipitation as $\phi_{\text {dry }} \rightarrow 0$.

\section{b. Relation to previous work}

Our results contrast with those of $\mathrm{CH} 18$, who found that precipitation efficiency was higher when soil moisture was lower $\left(\eta_{A}\right.$ and $\eta_{E}$ in their notation are proportional to $\epsilon_{\min }$ and $\epsilon_{\max }$ in our 

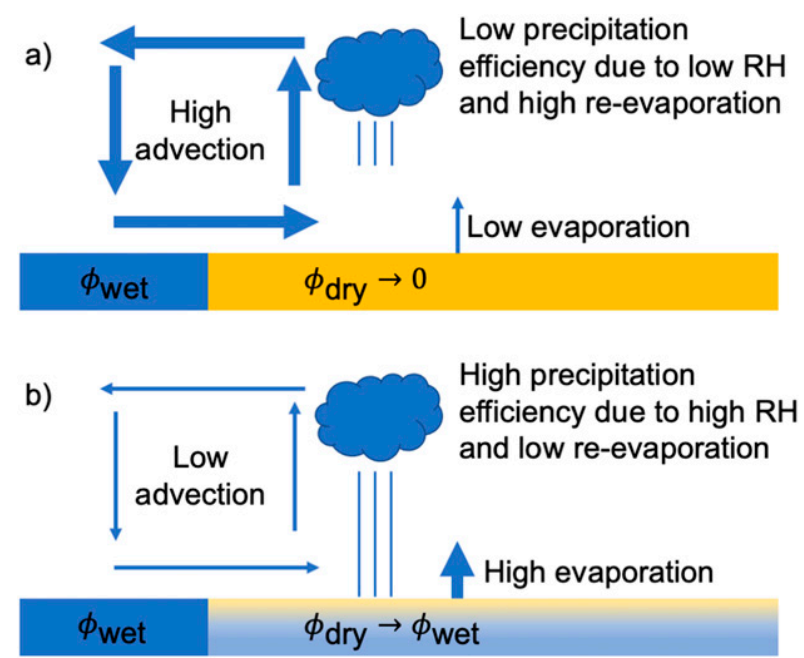

FIG. 10. Schematic of the main physical processes in two limiting cases. (a) As $\phi_{\text {dry }} \rightarrow 0, E_{\text {dry }}$ and $\epsilon_{\text {dry }}$ decrease, while $A_{\text {dry }}$ increases. Since changes in $E_{\mathrm{dry}}$ and $A_{\mathrm{dry}}$ approximately cancel out, changes in $\epsilon_{\text {dry }}$ dominate and $P_{\text {dry }}$ decreases. (b) As $\phi_{\text {dry }} \rightarrow \phi_{\text {wet }}, E_{\text {dry }}$ and $\epsilon_{\text {dry }}$ increase, while $A_{\text {dry }}$ decreases. Since changes in $E_{\text {dry }}$ and $A_{\text {dry }}$ approximately cancel out, changes in $\epsilon_{\mathrm{dry}}$ dominate and $P_{\mathrm{dry}}$ increases.

notation, respectively). The reverse is true in our simulations. Why? On the one hand, $\mathrm{CH} 18$ did not include such dry soil moisture cases in their simulations as those in our study. On the other hand, $\mathrm{CH} 18$ prescribed an atmospheric sounding as an initial condition in their simulations. In contrast, the atmosphere equilibrates with the land surface in our simulations, so that dry soil leads to a dry atmosphere with high precipitation reevaporation and low precipitation efficiency. The dominant mechanism linking soil moisture and precipitation in our simulations is, therefore, missing in their simulations, explaining the difference.

\section{c. Limitations}

Figure 10 is a schematic and is necessarily incomplete. Differences between microphysics schemes cause additional variability that is neglected in our conceptual model (Fig. 9). Using the M2005 scheme, the conversion efficiency exhibits a systematic increase with decreasing soil moisture at low soil moisture values (Fig. 8b), which likely explains the peak in precipitation (Fig. 7a) at low soil moisture values using that scheme. We chose not to include this feature in our conceptual model, as it is not robust to changes in the microphysics scheme. However, it would be straightforward to include dependence of $\alpha$ on soil moisture and to reproduce the peak in precipitation, if desired.

Our RCE simulations are a highly idealized analog of a wet soil in an otherwise dry continental environment. Their simplicity facilitates insight, but at the price of decreased realism. For example, our simulations use a fixed geometry for the dry and wet patches, yet the relative sizes of the dry and moist patches have been shown to influence total precipitation (Rieck et al. 2014). In addition, the effects of a mean wind are not included in our simulations. The presence of a mean wind tends to weaken the mesoscale circulation and reduce precipitation over the dry patch
(Froidevaux et al. 2014; Baur et al. 2018; Schneider et al. 2019). Nevertheless, RCE over land may be a useful first-order model of the Sahel and has been proposed as a model to explain some of the observed variability in the width of the intertropical convergence zone over the region (Hohenegger and Stevens 2018).

\section{Conclusions}

Using cloud-permitting simulations of an idealized soil moisture gradient, we have identified a new mechanism by which soil moisture can control precipitation: all else being equal, drier soils can lead to a drier atmosphere with more precipitation reevaporation and less surface precipitation. Including the new mechanism reverses the sign of the soil moisture-precipitation relation identified in the most similar previous studies (two patches with different soil moisture, and no relaxation to a mean wind profile): over the dry patch, decreasing soil moisture decreases precipitation in our study but typically increases it in previous studies.

Unlike similar previous studies, our simulations allow the atmosphere to first equilibrate to the land surface state (with soil moisture fixed, to ensure the soil moisture gradient is not eliminated), which is then used as the initial atmospheric sounding in our simulations with interactive soil moisture. Previous studies specified an arbitrary initial condition atmospheric sounding, which effectively eliminated some important coupling between the land and atmosphere that is critical to the precipitation reevaporation mechanism we identify.

The mechanism is distinct from other proposed links between soil moisture and large-scale precipitation efficiency proposed over a homogeneous land surface. A proposed mechanism based on the boundary layer moist enthalpy budget (Schär et al. 1999) does not translate to the heterogeneous land surface case studied here. Another proposed mechanism based on the microphysical conversion efficiency (Cioni and Hohenegger 2017) is found to be of secondary importance in our simulations compared to the new precipitation reevaporation mechanism.

The mechanism we identify may be relevant in linking land surface conditions to climate sensitivity, since climate sensitivity is strongly related to precipitation efficiency in a warming environment (Mauritsen et al. 2012; Zhao 2014; Tomassini et al. 2015). Future work is needed to better connect the results of these idealized simulations to mesoscale circulations in realworld environments like the Sahel: for instance, by relaxing the radiative-convective equilibrium simplification of the atmosphere and by incorporating the effects of vegetation at the land surface. In addition, as near-surface RH is likely to decrease over land as the climate warms (O'Gorman and Muller 2010; Simmons et al. 2010; Byrne and O'Gorman 2016), and nearsurface $\mathrm{RH}$ is correlated with precipitation efficiency in our simulations, it may be interesting to further investigate the likely impact of declining continental RH on precipitation efficiency.

Acknowledgments. K.A.M. acknowledges funding from the Dean's Competitive Fund for Promising Scholarship from Harvard University. We thank Dr. Marat Khairoutdinov for providing the models used in this study (SAM and SLM) and Dr. Nick Lutsko for providing code for estimating the conversion and sedimentation efficiencies from SAM outputs. 
Data availability statement. The datasets generated for this study are available from the corresponding author on request.

\section{REFERENCES}

Alfieri, L., P. Claps, P. D’Odorico, F. Laio, and T. M. Over, 2008: An analysis of the soil moisture feedback on convective and stratiform precipitation. J. Hydrometeor., 9, 280-291, https:// doi.org/10.1175/2007JHM863.1.

Almazroui, M., F. Saeed, S. Saeed, M. N. Islam, M. Ismail, N. A. B. Klutse, and M. H. Siddiqui, 2020: Projected change in temperature and precipitation over Africa from CMIP6. Earth Syst. Environ., 4, 455-475, https://doi.org/10.1007/s41748-02000161-x.

Anthes, R. A., 1984: Enhancement of convective precipitation by mesoscale variations in vegetative covering in semiarid regions. J. Appl. Meteor. Climatol., 23, 541554, https://doi.org/10.1175/1520-0450(1984)023<0541: $\mathrm{EOCPBM}>2.0 . \mathrm{CO} ; 2$.

Avissar, R., and Y. Liu, 1996: Three-dimensional numerical study of shallow convective clouds and precipitation induced by land surface forcing. J. Geophys. Res., 101, 7499-7518, https:// doi.org/10.1029/95JD03031.

Barthlott, C., and N. Kalthoff, 2011: A numerical sensitivity study on the impact of soil moisture on convection-related parameters and convective precipitation over complex terrain. J. Atmos. Sci., 68, 2971-2987, https://doi.org/10.1175/JAS-D11-027.1.

Baur, F., C. Keil, and G. C. Craig, 2018: Soil moisture-precipitation coupling over central Europe: Interactions between surface anomalies at different scales and the dynamical implication. Quart. J. Roy. Meteor. Soc., 144, 2863-2875, https://doi.org/ 10.1002/qj.3415.

Betts, A. K., 2000: Idealized model for equilibrium boundary layer over land. J. Hydrometeor., 1, 507-523, https://doi.org/10.1175/ 1525-7541(2000)001<0507:IMFEBL > 2.0.CO;2.

— , and J. H. Ball, 1998: FIFE surface climate and site-average dataset 1987-89. J. Atmos. Sci., 55, 1091-1108, https://doi.org/ 10.1175/1520-0469(1998)055<1091:FSCASA > 2.0.CO;2.

Bretherton, C. S., M. E. Peters, and L. E. Back, 2004: Relationships between water vapor path and precipitation over the tropical oceans. J. Climate, 17, 1517-1528, https://doi.org/10.1175/15200442(2004)017<1517:RBWVPA>2.0.CO;2.

Byrne, M. P., and P. A. O'Gorman, 2016: Understanding decreases in land relative humidity with global warming: Conceptual model and GCM simulations. J. Climate, 29, 9045-9061, https://doi.org/10.1175/JCLI-D-16-0351.1.

Chen, F., and R. Avissar, 1994: Impact of land-surface moisture variability on local shallow convective cumulus and precipitation in large-scale models. J. Appl. Meteor. Climatol., 33, 1382-1401, https://doi.org/10.1175/1520-0450(1994)033<1382: IOLSMV $>2.0 . \mathrm{CO} ; 2$

Chen, S., K. A. McColl, A. Berg, and Y. Huang, 2021: Surface flux equilibrium estimates of evapotranspiration at large spatial scales. J. Hydrometeor., 22, 765-779, https://doi.org/10.1175/ JHM-D-20-0204.1.

Cheng, W. Y., and W. R. Cotton, 2004: Sensitivity of a cloudresolving simulation of the genesis of a mesoscale convective system to horizontal heterogeneities in soil moisture initialization. J. Hydrometeor., 5, 934-958, https://doi.org/10.1175/ 1525-7541(2004)005<0934:SOACSO >2.0.CO;2.

Cioni, G., and C. Hohenegger, 2017: Effect of soil moisture on diurnal convection and precipitation in large-eddy simulations.
J. Hydrometeor., 18, 1885-1903, https://doi.org/10.1175/JHM-D16-0241.1.

_- and —_, 2018: A simplified model of precipitation enhancement over a heterogeneous surface. Hydrol. Earth Syst. Sci., 22, 3197-3212, https://doi.org/10.5194/hess-223197-2018.

Dirmeyer, P. A., 1995: Problems in initializing soil wetness. Bull. Amer. Meteor. Soc., 76, 2234-2240, https://doi.org/10.1175/ 1520-0477-76.11.2211.

- 2000: Using a global soil wetness dataset to improve seasonal climate simulation. J. Climate, 13, 2900-2922, https://doi.org/ 10.1175/1520-0442(2000)013<2900:UAGSWD>2.0.CO;2.

Eltahir, E. A., 1998: A soil moisture-rainfall feedback mechanism: 1. Theory and observations. Water Resour. Res., 34, 765-776, https://doi.org/10.1029/97WR03499.

Entekhabi, D., I. Rodriguez-Iturbe, and F. Castelli, 1996: Mutual interaction of soil moisture state and atmospheric processes. J. Hydrol., 184, 3-17, https://doi.org/10.1016/0022-1694(95) 02965-6.

Findell, K. L., and E. A. Eltahir, 2003: Atmospheric controls on soil moisture-boundary layer interactions. Part II: Feedbacks within the continental United States. J. Hydrometeor., 4, 570-583, https:// doi.org/10.1175/1525-7541(2003)004<0570:ACOSML>2.0.CO;2.

Fischer, E. M., S. I. Seneviratne, P. L. Vidale, D. Lüthi, and C. Schär, 2007: Soil moisture-atmosphere interactions during the 2003 European summer heat wave. J. Climate, 20, 50815099, https://doi.org/10.1175/JCLI4288.1.

Froidevaux, P., L. Schlemmer, J. Schmidli, W. Langhans, and C. Schär, 2014: Influence of the background wind on the local soil moisture-precipitation feedback. J. Atmos. Sci., 71, 782799, https://doi.org/10.1175/JAS-D-13-0180.1.

Gallus, W. A., and M. Segal, 2000: Sensitivity of forecast rainfall in a Texas convective system to soil moisture and convective parameterization. Wea. Forecasting, 15, 509-525, https://doi.org/ 10.1175/1520-0434(2000)015<0509:SOFRIA >2.0.CO;2.

$\mathrm{Gu}, \mathrm{L}$., and Coauthors, 2006: Direct and indirect effects of atmospheric conditions and soil moisture on surface energy partitioning revealed by a prolonged drought at a temperate forest site. J. Geophys. Res., 111, D16102, https://doi.org/10.1029/ 2006JD007161.

Hohenegger, C., and B. Stevens, 2018: The role of the permanent wilting point in controlling the spatial distribution of precipitation. Proc. Natl. Acad. Sci. USA, 115, 5692-5697, https:// doi.org/10.1073/pnas.1718842115.

— - P. Brockhaus, C. S. Bretherton, and C. Schär, 2009: The soil moisture-precipitation feedback in simulations with explicit and parameterized convection. J. Climate, 22, 5003-5020, https://doi.org/10.1175/2009JCLI2604.1.

$\mathrm{Hu}$, Q., and D. A. Randall, 1994: Low-frequency oscillations in radiative-convective systems. J. Atmos. Sci., 51, 10891099, https://doi.org/10.1175/1520-0469(1994)051<1089: LFOIRC $>2.0 . \mathrm{CO} ; 2$.

Idso, S., R. Jackson, R. Reginato, B. Kimball, and F. Nakayama, 1975: The dependence of bare soil albedo on soil water content. J. Appl. Meteor., 14, 109-113, https://doi.org/10.1175/ 1520-0450(1975)014<0109:TDOBSA > 2.0.CO;2.

Khairoutdinov, M. F., and D. A. Randall, 2003: Cloud resolving modeling of the ARM summer 1997 IOP: Model formulation, results, uncertainties, and sensitivities. J. Atmos. Sci., 60, 607-625, https://doi.org/10.1175/1520-0469(2003) 060<0607:CRMOTA > 2.0.CO;2.

Kiehl, J., J. Hack, G. Bonan, B. Boville, D. Williamson, and P. Rasch, 1998: The National Center for Atmospheric Research Community 
Climate Model: CCM3. J. Climate, 11, 1131-1149, https://doi.org/ 10.1175/1520-0442(1998)011<1131:TNCFAR>2.0.CO;2.

Lee, J. M., and M. Khairoutdinov, 2015: A simplified land model (SLM) for use in cloud-resolving models: Formulation and evaluation. J. Adv. Model. Earth Syst., 7, 1368-1392, https:// doi.org/10.1002/2014MS000419.

Lutsko, N. J., and T. W. Cronin, 2018: Increase in precipitation efficiency with surface warming in radiative-convective equilibrium. J. Adv. Model. Earth Syst., 10, 2992-3010, https:// doi.org/10.1029/2018MS001482.

Lynn, B. H., W.-K. Tao, and P. J. Wetzel, 1998: A study of landscape-generated deep moist convection. Mon. Wea. Rev., 126, 928-942, https://doi.org/10.1175/1520-0493(1998) $126<0928$ :ASOLGD > 2.0.CO;2.

Manabe, S., 1969: Climate and the ocean circulation: I. The atmospheric circulation and the hydrology of the Earth's surface. Mon. Wea. Rev., 97, 739-774, https://doi.org/10.1175/ 1520-0493(1969)097<0739:CATOC >2.3.CO;2.

Martin, W. J., and M. Xue, 2006: Sensitivity analysis of convection of the 24 May 2002 IHOP case using very large ensembles. Mon. Wea. Rev., 134, 192-207, https://doi.org/ 10.1175/MWR3061.1.

Mauritsen, T., and Coauthors, 2012: Tuning the climate of a global model. J. Adv. Model. Earth Syst., 4, M00A01, https://doi.org/ 10.1029/2012MS000154.

McColl, K. A., and A. J. Rigden, 2020: Emergent simplicity of continental evapotranspiration. Geophys. Res. Lett., 47, e2020GL087101, https://doi.org/10.1029/2020GL087101.

— , S. H. Alemohammad, R. Akbar, A. G. Konings, S. Yueh, and D. Entekhabi, 2017: The global distribution and dynamics of surface soil moisture. Nat. Geosci., 10, 100-104, https://doi.org/ 10.1038/ngeo2868.

— , G. D. Salvucci, and P. Gentine, 2019: Surface flux equilibrium theory explains an empirical estimate of water-limited daily evapotranspiration. J. Adv. Model. Earth Syst., 11, 2036-2049, https://doi.org/10.1029/2019MS001685.

Miller, S. T. K., B. D. Keim, R. W. Talbot, and H. Mao, 2003: Sea breeze: Structure, forecasting, and impacts. Rev. Geophys., $\mathbf{4 1}$, 1011, https://doi.org/10.1029/2003RG000124.

Moon, H., B. P. Guillod, L. Gudmundsson, and S. I. Seneviratne, 2019: Soil moisture effects on afternoon precipitation occurrence in current climate models. Geophys. Res. Lett., 46, 18611869, https://doi.org/10.1029/2018GL080879.

Morrison, H., J. Curry, and V. Khvorostyanov, 2005: A new double-moment microphysics parameterization for application in cloud and climate models. Part I: Description. J. Atmos. Sci., 62, 1665-1677, https://doi.org/10.1175/JAS3446.1.

- , G. Thompson, and V. Tatarskii, 2009: Impact of cloud microphysics on the development of trailing stratiform precipitation in a simulated squall line: Comparison of one- and two-moment schemes. Mon. Wea. Rev., 137, 991-1007, https:// doi.org/10.1175/2008MWR2556.1.

O'Gorman, P., and C. J. Muller, 2010: How closely do changes in surface and column water vapor follow Clausius-Clapeyron scaling in climate change simulations? Environ. Res. Lett., 5, 025207, https://doi.org/10.1088/1748-9326/5/2/025207.

Ookouchi, Y., M. Segal, R. Kessler, and R. Pielke, 1984: Evaluation of soil moisture effects on the generation and modification of mesoscale circulations. Mon. Wea. Rev., 112, 2281-2292, https://doi.org/10.1175/1520-0493(1984) $112<2281$ :EOSMEO $>2.0 . \mathrm{CO} ; 2$.

Pal, J. S., and E. A. Eltahir, 2001: Pathways relating soil moisture conditions to future summer rainfall within a model of the land-atmosphere system. J. Climate, 14, 1227-1242, https:// doi.org/10.1175/1520-0442(2001)014<1227:PRSMCT>2.0.CO;2.

Patton, E. G., P. P. Sullivan, and C.-H. Moeng, 2005: The influence of idealized heterogeneity on wet and dry planetary boundary layers coupled to the land surface. J. Atmos. Sci., 62, 20782097, https://doi.org/10.1175/JAS3465.1.

Pielke, R. A., Sr., G. E. Liston, J. L. Eastman, L. Lu, and M. Coughenour, 1999: Seasonal weather prediction as an initial value problem. J. Geophys. Res., 104, 19463-19479, https://doi.org/10.1029/1999JD900231.

Ray, D. K., U. S. Nair, R. M. Welch, Q. Han, J. Zeng, W. Su, T. Kikuchi, and T. J. Lyons, 2003: Effects of land use in southwest Australia: 1. Observations of cumulus cloudiness and energy fluxes. J. Geophys. Res., 108, 4414, https://doi.org/ 10.1029/2002JD002654.

Rieck, M., C. Hohenegger, and C. C. van Heerwaarden, 2014: The influence of land surface heterogeneities on cloud size development. Mon. Wea. Rev., 142, 3830-3846, https://doi.org/ 10.1175/MWR-D-13-00354.1.

Robinson, F. J., S. Sherwood, and Y. Li, 2008: Resonant response of deep convection to surface hot spots. J. Atmos. Sci., 65, 276286, https://doi.org/10.1175/2007JAS2398.1.

Schär, C., D. Lüthi, U. Beyerle, and E. Heise, 1999: The soilprecipitation feedback: A process study with a regional climate model. J. Climate, 12, 722-741, https://doi.org/10.1175/ 1520-0442(1999)012<0722:TSPFAP $>2.0 . C O ; 2$.

Schneider, L., C. Barthlott, C. Hoose, and A. I. Barrett, 2019: Relative impact of aerosol, soil moisture, and orography perturbations on deep convection. Atmos. Chem. Phys., 19, 12 343-12 359, https://doi.org/10.5194/acp-19-12343-2019.

Segal, M., and R. Arritt, 1992: Nonclassical mesoscale circulations caused by surface sensible heat-flux gradients. Bull. Amer. Meteor. Soc., 73, 1593-1604, https://doi.org/10.1175/ 1520-0477(1992)073<1593:NMCCBS > 2.0.CO;2.

Seneviratne, S. I., D. Lüthi, M. Litschi, and C. Schär, 2006: Landatmosphere coupling and climate change in Europe. Nature, 443, 205-209, https://doi.org/10.1038/nature05095.

—_, T. Corti, E. L. Davin, M. Hirschi, E. B. Jaeger, I. Lehner, B. Orlowsky, and A. J. Teuling, 2010: Investigating soil moisture-climate interactions in a changing climate: A review. Earth-Sci. Rev., 99, 125-161, https://doi.org/10.1016/ j.earscirev.2010.02.004.

— , and Coauthors, 2013: Impact of soil moisture-climate feedbacks on CMIP5 projections: First results from the GLACECMIP5 experiment. Geophys. Res. Lett., 40, 5212-5217, https://doi.org/10.1002/grl.50956.

Simmons, A., K. Willett, P. Jones, P. Thorne, and D. Dee, 2010: Low-frequency variations in surface atmospheric humidity, temperature, and precipitation: Inferences from reanalyses and monthly gridded observational data sets. J. Geophys. Res., 115, D01110, https://doi.org/ 10.1029/2009JD012442.

Smolarkiewicz, P. K., and W. W. Grabowski, 1990: The multidimensional positive definite advection transport algorithm: Nonoscillatory option. J. Comput. Phys., 86, 355-375, https:// doi.org/10.1016/0021-9991(90)90105-A.

Sui, C.-H., X. Li, and M.-J. Yang, 2007: On the definition of precipitation efficiency. J. Atmos. Sci., 64, 4506-4513, https:// doi.org/10.1175/2007JAS2332.1.

Taylor, C. M., and T. Lebel, 1998: Observational evidence of persistent convective-scale rainfall patterns. Mon. Wea. Rev., 126, 1597-1607, https://doi.org/10.1175/1520-0493(1998)126<1597: OEOPCS $>2.0 . \mathrm{CO} ; 2$. 
, P. P. Harris, and D. J. Parker, 2010: Impact of soil moisture on the development of a Sahelian mesoscale convective system: A case-study from the AMMA special observing period. Quart. J. Roy. Meteor. Soc., 136, 456-470, https://doi.org/ 10.1002/qj.465.

-, A. Gounou, F. Guichard, P. P. Harris, R. J. Ellis, F. Couvreux, and M. De Kauwe, 2011: Frequency of Sahelian storm initiation enhanced over mesoscale soil-moisture patterns. Nat. Geosci., 4, 430-433, https://doi.org/10.1038/ngeo1173.

—, R. A. de Jeu, F. Guichard, P. P. Harris, and W. A. Dorigo, 2012: Afternoon rain more likely over drier soils. Nature, 489, 423-426, https://doi.org/10.1038/nature11377.

Tomassini, L., A. Voigt, and B. Stevens, 2015: On the connection between tropical circulation, convective mixing, and climate sensitivity. Quart. J. Roy. Meteor. Soc., 141, 1404-1416, https:// doi.org/10.1002/qj.2450.

Tuttle, S., and G. Salvucci, 2016: Empirical evidence of contrasting soil moisture-precipitation feedbacks across the United States. Science, 352, 825-828, https://doi.org/10.1126/ science.aaa7185.

Van Weverberg, K., N. P. van Lipzig, L. Delobbe, and D. Lauwaet, 2010: Sensitivity of quantitative precipitation forecast to soil moisture initialization and microphysics parametrization. Quart. J. Roy. Meteor. Soc., 136, 978-996, https://doi.org/10.1002/qj.611.

Zhao, M., 2014: An investigation of the connections among convection, clouds, and climate sensitivity in a global climate model. J. Climate, 27, 1845-1862, https://doi.org/10.1175/JCLID-13-00145.1. 